\title{
Influence of particle size and particle size distribution on toughening mechanisms in rubber-modified epoxies
}

\author{
R. A. PEARSON*, A. F. YEE \\ Department of Materials Science and Engineering, University of Michigan, Ann Arbor, MI \\ 48109, USA
}

\begin{abstract}
The principal toughening mechanism of a substantially toughened, rubber-modified epoxy has again been shown to involve internal cavitation of the rubber particles and the subsequent formation of shear bands. Additional evidence supporting this sequence of events which provides a significant amount of toughness enhancement, is presented. However, in addition to this well-known mechanism, more subtle toughening mechanisms have been found in this work. Evidence for such mechanisms as crack deflection and particle bridging is shown under certain circumstances in rubber-modified epoxies. The occurrence of these toughening mechanisms appears to have a particle size dependence. Relatively large particles provide only a modest increase in fracture toughness by a particle bridging/crack deflection mechanism. In contrast, smaller particles provide a significant increase in toughness by cavitation-induced shear banding. A critical, minimum diameter for particles which act as bridging particles exists and this critical diameter appears to scale with the properties of the neat epoxy. Bimodal mixtures of epoxies containing small and large particles are also examined and no synergistic effects are observed.
\end{abstract}

\section{Introduction}

Sultan and co-workers $[1,2]$ were among the first researchers to show that the fracture toughness of a brittle epoxy could be improved by the incorporation of rubber spheres of approximately $1 \mu \mathrm{m}$ diameter. Since their initial investigation, at least thirteen different toughening mechanisms have been proposed as being responsible for providing the increase in fracture toughness (see the recent review by Garg and Mai [3]). This profusion of ideas on the actual toughening mechanism may have slowed down progress in developing even tougher thermosetting materials because no clear direction had been established. Fortunately, the work by Kramer [4] clearly eliminates the possibility of having massive crazing as the toughening mechanism in epoxies because the cross-linked nature of these materials suppresses any tendency to craze. However, other mechanisms, such as rubber particle stretching, micro-cracking, shear banding, and crack deflection, could not be ruled out.

In our previous papers $[5,6]$ the micro-mechanical deformation mechanisms responsible for providing the increase in fracture toughness were shown to be internal cavitation of the rubber particles and the formation of shear bands. This deduction is consistent with those reached by Bascom and co-workers $[7,8]$ and Kinloch and co-workers [9-11]. Because the majority of the toughness is achieved by the dissipation of energy through shear band formation, the efficiency of this mechanism should depend on the properties of the epoxy matrix. Therefore, in a comple- mentary study [12], it was shown that even tougher epoxies could be produced by decreasing the crosslink density of the epoxy matrix. However, this crosslink density dependence may not be the only material parameter which influences the occurrence of the cavitation/shear banding mechanism.

Rubber-particle size appears to be another material parameter that influences the fracture toughness of rubber-modified epoxies. Kunz-Douglas et al. [13] have reported that large, $40 \mu \mathrm{m}$ particles are not as efficient in providing an increase in fracture toughness as smaller, $1 \mu \mathrm{m}$ particles. We show in this paper that this effect may have been incorrectly attributed to the difference in the tearing strength of the types of rubbers used (for a critique of the rubber stretching theory see Kinloch et al. [9]). Unfortunately, no alternative explanation to the rubber particle size effect has been offered until the work of Wu and Margolina [14, 15] who developed a correlation involving the interparticle distance as a critical parameter for those materials that are toughened via a shear yielding mechanism. This correlation predicts that smaller particles should be better toughening agents. However, Sultan and McGarry [2] have shown that $40 \mathrm{~nm}$ particles are not as efficient as larger, $1 \mu \mathrm{m}$ particles. At present, the optimal rubber particle size for toughening epoxies appears to be in the $0.1-5.0 \mu \mathrm{m}$ range and there is no rationale for this particle size effect.

Other researchers $[16,17]$ have claimed that the optimal particle size actually involves a bimodal distribution of particle sizes. However, the first of these

* Present address: Department of Materials Science and Engineering, Lehigh University, Bethleham, Pennsylvania 18015, USA. 
investigations [16] obtained a bimodal particle size distribution by the addition of bisphenol $\mathrm{A}$ which also acts as a chain extender, hence improving the toughenability of the matrix. Therefore, we contend that these claims have neglected the effect of cross-link density which has been shown to be quite substantial [12]. The second investigation [17] shows that a bimodal particle size distribution is more effective only at low strain rates. In summary, the underlying causes for both the particle size effect and possible particle size distribution effects have not been clearly established for rubber-modified epoxies.

The purpose of this paper is to deduce the underlying cause(s) for rubber particle size effect(s) in rubber-modified epoxies. This deduction involves the elucidation of the toughening mechanism for each type of rubber modification (large and small particles). An attempt to answer the question of the occurrence of synergism in rubber-modified epoxies with a bimodal particle size distribution is also made.

\section{Experimental procedure}

\subsection{Materials}

The materials used in this investigation include DER ${ }^{B}$ 331 resin which is a liquid diglycidyl ether of bisphenol-A (DGEBA) epoxy. Batches of $500 \mathrm{~g}$ were cured using five parts per hundred piperidine which was used as-received. Rubber-toughened epoxies were produced by adding either a liquid reactive rubber or a solid core/shell rubber. Several liquid rubbers were tried, including Hycar ${ }^{\circledR}$ CTBN $1300 \times 8$, CTBN 1300 $\times 31$, and CTB $2000 \times 162$ resins. The CTBNs are liquid copolymers of butadiene and acrylonitrile with carboxyl end-groups. The use of these liquid rubber resins produced precipitated rubber particles with a variety of diameters (see Table I). Detailed properties and descriptions of these liquid rubbers can be found elsewhere [16]. The core/shell rubber used was of an emulsified, methacrylated butadiene-styrene (MBS) type produced commercially under the trade name Acryloid ${ }^{\circledR}$ KM 653 resin. The average particle diameter for this modifier is $0.2 \mu \mathrm{m}$. This core/shell rubber was supplied in powder form and used as-received.

These materials were cured using the following schedule. First the DGEBA epoxy and rubber mixture was heated to approximately $80^{\circ} \mathrm{C}$ and degassed while stirring. The degassing stage could take as long as $1 \mathrm{~h}$. Then the vacuum was removed and piperidine

TABLE I Uniaxial tensile properties of some rubber-modified epoxies

\begin{tabular}{llll}
\hline Formulaticn & $\begin{array}{l}\text { Particle size } \\
(\mu \mathrm{m})\end{array}$ & $\begin{array}{l}E \\
(\mathrm{GPa})\end{array}$ & $\begin{array}{l}\sigma_{\mathrm{y}} \\
(\mathrm{MPa})\end{array}$ \\
\hline DGEBA/PIP & 0 (neat resin) & 3.0 & 74 \\
DGEBA/PIP/CTB-162 & $\leqslant 200$ & 2.5 & 55 \\
DGEBA/PIP/CTB/CTBN & $1-2,100-200$ & 2.5 & - \\
DGEBA/PIP/CTBN-8 & $1-2$ & 2.6 & 63 \\
DGEBA/PIP/CTBN-31 & $1-2,10-20$ & 2.6 & 60 \\
DGEBA/PIP/MBS & $\sim 0.2$ & 2.6 & 60 \\
DGEBA/PIP/MBS/CTBN & $0.2,1-2$ & 2.6 & 61 \\
\hline
\end{tabular}

Note: all rubber-modified epoxies contain 10 p.h.r. rubber. was added while stirring slowly. The mixture was again degassed ( $\sim 15 \mathrm{~min})$ and was poured into a preheated mould at $120^{\circ} \mathrm{C}$. The mould was placed in an air-circulating oven at $120^{\circ} \mathrm{C}$ for $16 \mathrm{~h}$. After this time the mould was removed from the oven and allowed to cool gradually to room temperature.

\subsection{Morphology}

Particle size and particle size distributions were determined using optical microscopy (OM) and scanning electron microscopy (SEM). Average particle diameters were determined from an average of at least 20 observations. This characterization of particle size is somewhat crude but sufficient for the present purposes because the size of the particles has been varied by three orders of magnitude $(\sim 0.2-200 \mu \mathrm{m})$. Clearly, bimodal particle size distributions exist for those materials containing a $50 / 50$ mixture of two types of rubber particle.

\subsection{Fracture toughness evaluation}

In this investigation the fracture toughness was measured by applying linear elastic fracture mechanics (LEFM). The critical stress intensity factor in plane strain, $K_{\mathrm{IC}}$, was determined using a single-edge notched (SEN) type specimen $(6.4 \mathrm{~mm} \times 12.7 \mathrm{~mm}$ $\times 80 \mathrm{~mm})$ in a three-point bending geometry. These specimens were precracked by striking a razor blade, previously chilled in liquid nitrogen, with a rubber mallet. The reported $K_{\mathrm{IC}}$ values are the average of a minimum of six tests. These tests were performed using a servohydraulic materials testing machine at a piston rate of $2.54 \mathrm{~mm} \mathrm{~s}^{-1}$. A computer interface controlled the machine and captured the data. An HP model 310 computer was programmed to calculate the critical stress intensity factor using the following relations [18]

$$
K_{\mathrm{IC}}=Y \frac{2 P S a^{1 / 2}}{3 t w^{2}}
$$

where $P$ is the critical load for crack propagation, $S$ the length of the span (mm), $a$ the crack length (mm), $t$ the thickness $(\mathrm{mm}), w$ the width $(\mathrm{mm})$ and $Y$ a nondimensional shape factor given by

$$
\begin{aligned}
Y= & 1.9-3.07(a / w)+14.53(a / w)^{2} \\
& -25.11(a / w)^{3}+25.80(a / w)^{4}
\end{aligned}
$$

The effect of crack tip plasticity on the validity of the $K$ measurements was evaluated using the standard equation which determines whether the thickness is large enough to provide plane strain constraint

$$
t>2.5\left(K_{\mathrm{IC}} / \sigma_{\mathrm{y}}\right)
$$

Strain energy release rates, $G_{\mathrm{IC}}$, may be calculated from the stress intensity values using the following relationship

$$
K_{\mathrm{IC}}^{2}=E^{*} G_{\mathrm{IC}}
$$

where $E^{*}$ is the effective modulus which in plane strain is equal to

$$
E^{*}=E /\left(1-v^{2}\right)
$$


and $E$ and $v$ are Young's modulus and Poisson's ratio, respectively, measured in uniaxial tension.

\subsection{Scanning electron microscopy}

The fracture surfaces of the SEN specimens used to determine fracture toughness were examined using a Hitachi S800 scanning electron microscope. The conventional secondary electron imaging technique was used. Samples were coated with a thin layer of gold-palladium to reduce any charge build-up on the fracture surface.

\subsection{Uniaxial tensile dilatometry}

The tensile dilatometry technique was employed in an effort to provide additional insight in the mechanism by which the rubber-modified epoxies are toughened. The technique used in this investigation is modelled after that used by Bucknall [19] except that a constant displacement rate rather than a constant load was used. Details of the technique are given elsewhere [20]. In brief, ASTM D-638 type I tensile specimens are prepared using a high-speed router. Cut surfaces are polished with fine emery paper. Three specimens tested for each formulation. An ASTM D638 standard stroke rate of $50 \mathrm{~mm} \mathrm{~min}^{-1}$ is used. An Instron servohydraulic testing machine equipped with two strain conditioners and a computer interface is used to perform these tests. Two extensometers with the requisite sensitivity are used to measure the longitudinal and lateral (width only) strains. The data analysis was performed using an HP 310 computer programmed to provide stress-strain as well as volume strainlongitudinal strain plots. The volume strain was plotted up to the point of necking or fracture. Young's modulus was obtained from a linear least squares fit of the stress-strain data taken from $0.1 \%-0.5 \%$ strain. The maximum in the engineering stress is reported here as the yield stress.

\subsection{Observation of crack tip mechanisms}

The double-notched four-point bend method, a relatively new testing technique for polymeric materials, was used to examine a mature plastic zone at a crack tip $[21,22]$. The principle of the technique is simple. First, two edge cracks of equal length are generated in

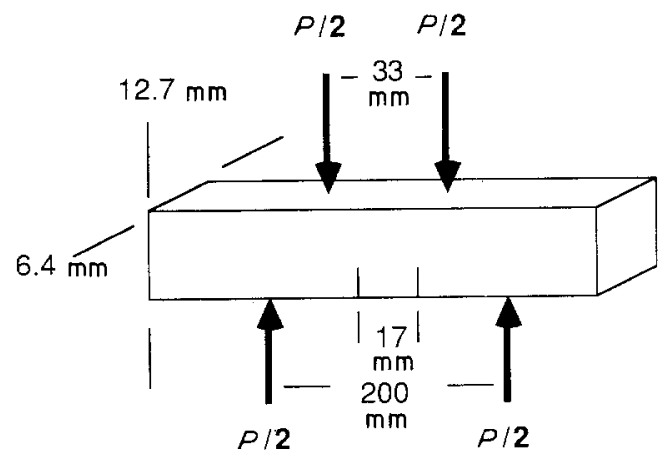

Figure 1 A schematic illustration of the double-notched four-point bending (DN-4PB) test geometry. a bend specimen $(6.4 \mathrm{~mm} \times 12.7 \mathrm{~mm} \times 125 \mathrm{~mm})$. Next, the bend specimen is loaded using a four-point bending geometry where the two cracks are located on the tensile side of the specimen within the minor span. Fig. 1 is a schematic drawing showing details of the test. Owing to stress intensification at the crack tips, plastics zones are formed at each crack tip upon loading. Because the cracks can never be identical, one of the cracks becomes critical and propagates in an unstable manner, thus unloading the other crack which immediately becomes stationary. This stationary crack containing a mature plastic zone can be inspected using the petrographic polishing technique described in Section 2.7 .

\subsection{Optical microscopy}

OM was employed to examine the subsurface damage in tensile, four-point and three-point bend specimens. However, a section thin enough to transmit light is required. In this investigation thin sections were produced using petrographic polishing. The details of the petrographic polishing technique have been published by Holik et al. [23]. In brief, sections taken from deformed specimens (either tensile, three-point or four-point bend) are potted in a room-temperature curing epoxy. These samples are then roughly ground, finely ground, roughly polished, and then finely polished. The polished surface is then mounted on to a clean glass slide using an optically clear epoxy. The sample and slide are allowed to cure overnight at room temperature. Excess material is removed using a diamond saw and the sample is again ground and polished until the plane of interest is finally reached. Useful thin sections ranged from $200-20 \mu \mathrm{m}$ thick, depending upon the rubber particle size. All samples are viewed using a Nikon Microphot II microscope using either polarized or crossed-polarized light. A quarter wave plate is sometimes used to enhance the contrast of the birefringent regions.

\section{Results}

\subsection{Particle size distributions}

Table I contains a summary of the range of particle sizes investigated in this work. Particles ranging from $0.2-200 \mu \mathrm{m}$ diameter have been observed. In addition to the neat epoxy, Table I contains information on three materials that contain rubber with a unimodal particle size distribution and three other materials that contain rubber particles with a bimodal size distribution. The 10 p.h.r. CTB-modified epoxy shows some signs of segregation, as some of the rubber floats to the top of the vertical mould. However, the Young's modulus and yield stress suggest that the volume fraction of CTB particles are comparable to the other rubber-modified materials.

\subsection{Fracture toughness assessment}

Table I also contains the fracture toughness results. Note that all values were obtained from specimens that satisfy the conditions for plane strain constraint. 
The effect of particle size is evident. Large, $100 \mu \mathrm{m}$ diameter particles are not as efficient in providing a toughening effect, whereas small, $0.1 \mu \mathrm{m}$ diameter particles appear to be the most efficient and provide over a ten-fold increase in fracture toughness. Interestingly, the materials containing a bimodal distribution of particle sizes do not display any marked synergism, i.e. the fracture toughness values are no greater than the value obtained for the smallest rubber particle size. However, the 50/50 blend of CTB-162 and CTBN-8 results in a fracture toughness which approaches the value of 10 p.h.r. CTBN-8. This result is discussed further in Section 4.3.

\subsection{Fracture surface inspection}

Figs 2-10 are scanning electron micrographs taken from the fracture surface of SEN-3PB specimens. It is common practice in the polymer field to use micrographs of this type to deduce the toughening mechanism. We shall attempt to show that this practice can be very misleading and that events occurring below the fracture surface responsible for the toughening effect may not be the same as those on the fracture surface. The fracture surface of a 3PB specimen of the neat resin is shown in Fig. 2. The fracture surface is nearly mirror-like, which indicates that very little plasticity has occurred. Fig. 3 shows the fracture surface of the DER 331/Pip/CTB(10) material which contains relatively large particles. Some welts on the surface of the matrix phase may indicate the occurrence of microcracking or bifurcation which can produce a modest toughening effect.

The remaining rubber-modified epoxies exhibit a stress-whitened zone on the fracture surface of the 3PB specimens. This zone forms during the loading

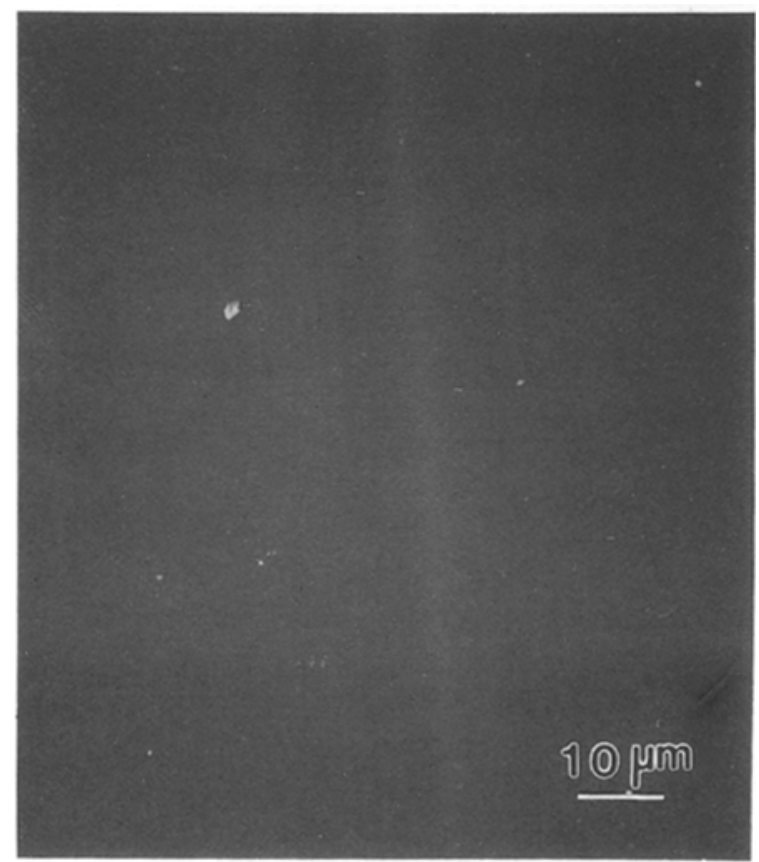

Figure 2 Scanning electron micrograph of the fracture surface of a 3PB specimen of DER 331/Pip, taken near the precrack arrest region. Note the absence of any plastic deformation or surface features.

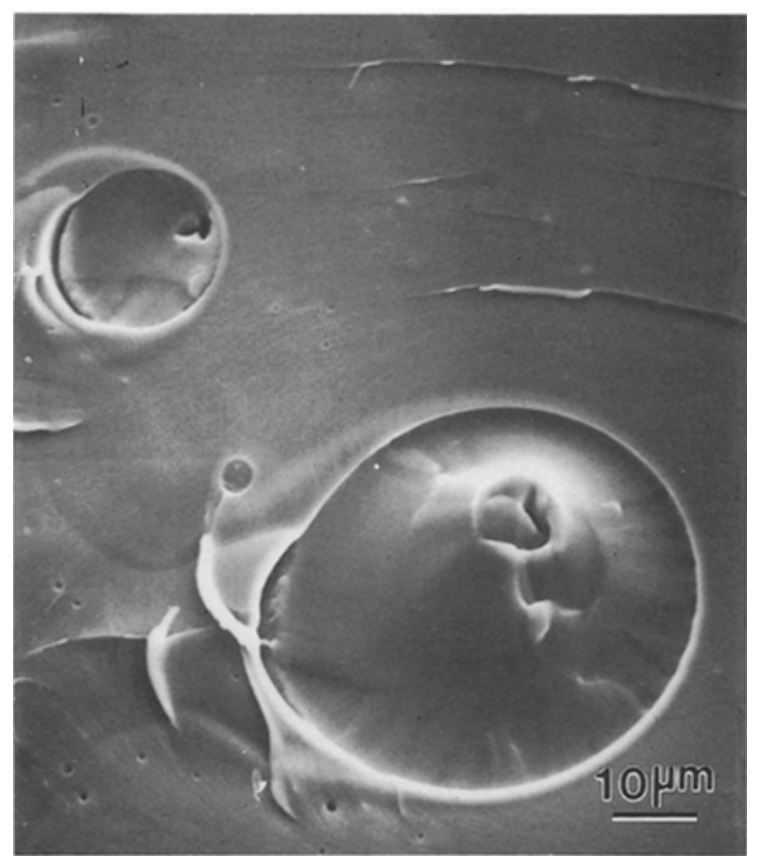

Figure 3 Scanning electron micrograph of the fracture surface of a 3PB specimen of DER 331/Pip/CTB(10), taken near the precrack arrest region.

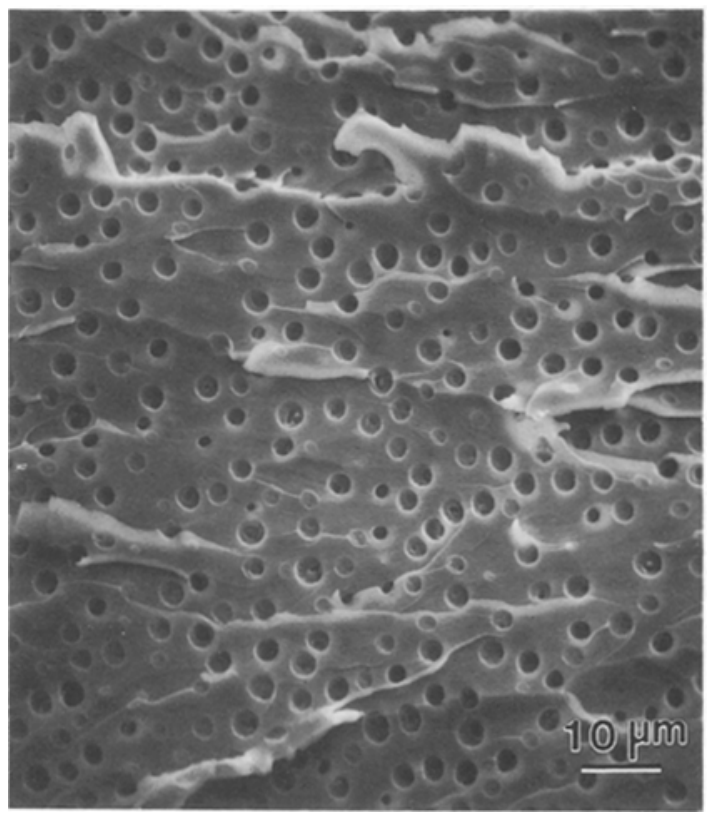

Figure 4 Scanning electron micrograph of the fracture surface of a $3 \mathrm{~PB}$ specimen of DER 331/Pip/CTBN-8(10), taken near the precrack arrest region (stress-whitened zone).

sequence and the size of this zone is proportional to the observed increase in fracture toughness. Therefore, examination of this zone is reasonable for elucidation of the toughening mechanism. Fig. 4 shows the stresswhitened region in the DER 331/Pip/CTBN-8(10) material. In contrast to the neat epoxy, the rubbertoughened epoxies exhibit microplasticity in terms of permanently dilated cavities which can be seen on the fracture surface. In a previous paper [6], we have shown that these cavities are lined with rubber, which suggests that the particles have cavitated internally. A micrograph of the same fracture surface, but at a 


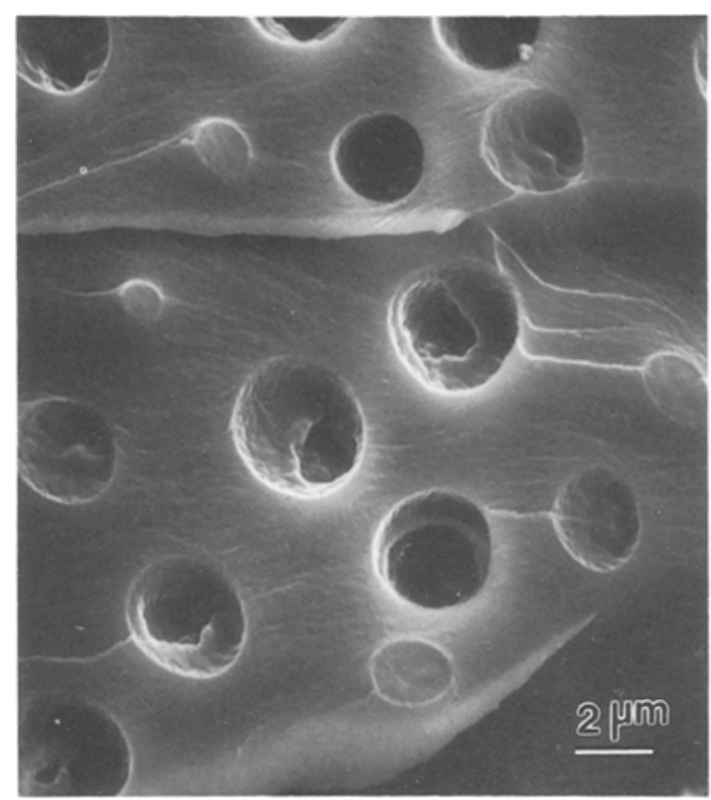

Figure 5 Same as Fig. 4 but at a higher magnification.

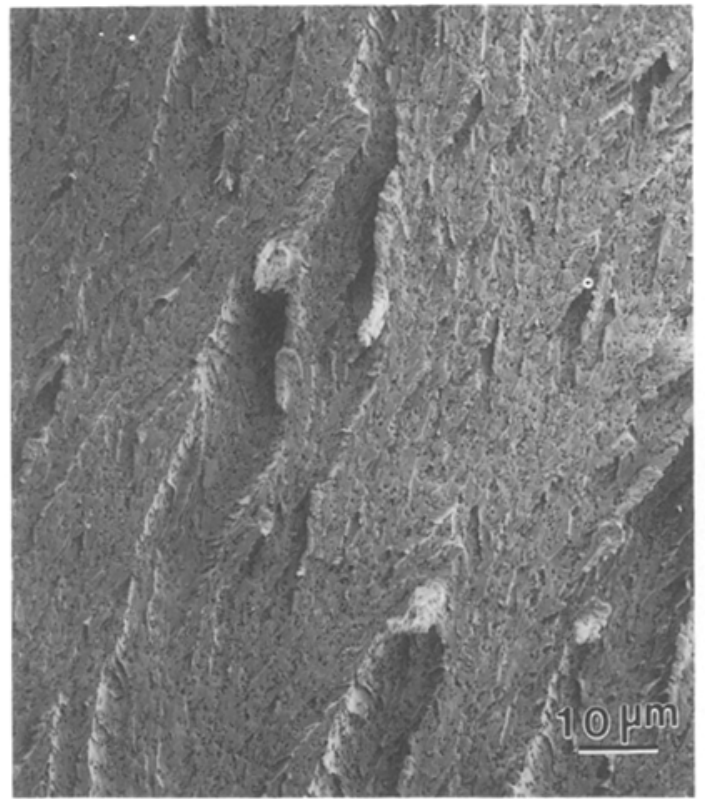

Figure 6 Scanning electron micrograph of the fracture surface of a 3PB specimen of DER 331/Pip/MBS(10), taken near the precrack arrest region (stress-whitened zone).

higher magnification is shown in Fig. 5. The surfaces of these cavities have a texture which is probably due to the remnants of the rubber phase. We show in Sections 3.5 and 3.6 additional evidence to support this observation of internal cavitation. Fig. 6 shows the stress-whitened region in the DER 331/Pip/ MBS(10) material. The fracture surface contains more welts and the size of the welts is significantly smaller. Fig. 7 shows the same fracture surface but at a higher magnification. These rubber particles also cavitate and the resultant voids are numerous. There appears to be an agglomeration problem as the concentration of rubber particles is not uniform. Despite the nonuniform dispersion of rubber particles, this material exhibits the greatest fracture toughness value measured in this investigation. The micrograph in Fig. 8 is

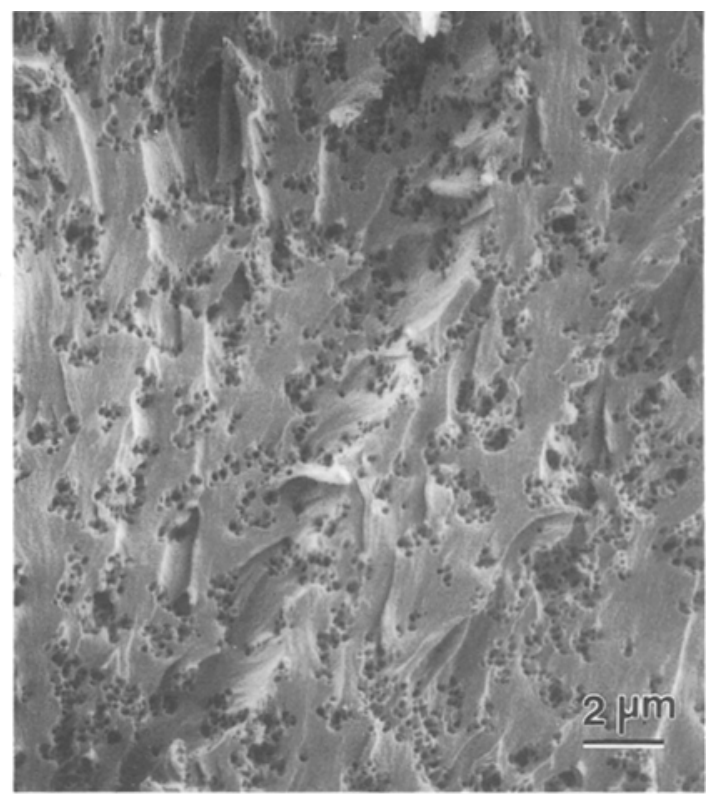

Figure 7 Same as Fig. 6 but at a higher magnification.

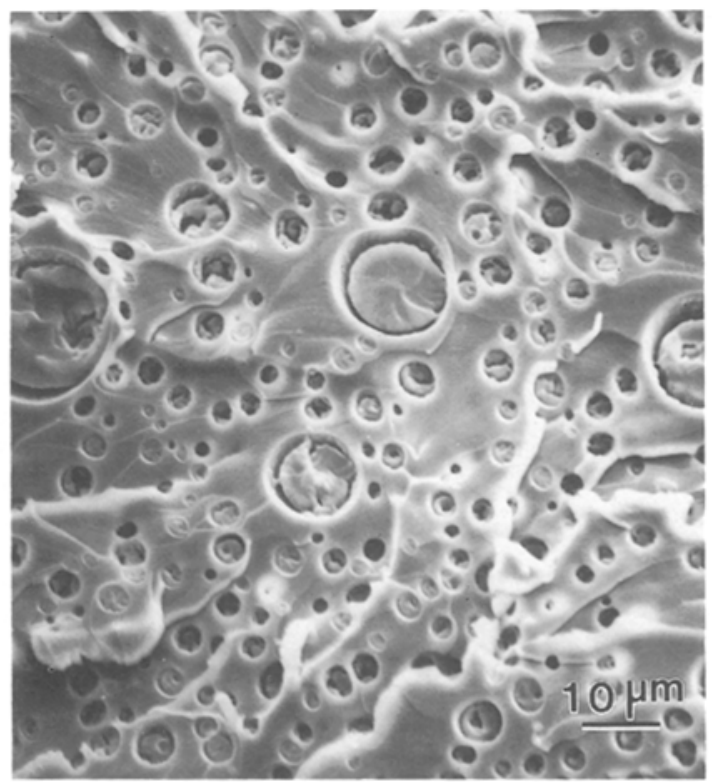

Figure 8 Scanning electron micrograph of the fracture surface of a 3PB specimen of DER 331/Pip/CTBN-31(10), taken near the precrack arrest region (stress-whitened zone).

of the stress-whitened region in the DER 331/ Pip/CTBN-31(10) material. The bimodal particle size distribution for this material is clearly evident. Note that the larger particles appear to be debonding from the epoxy matrix. Later sections will show that the adhesion between the two phases is actually quite good, in fact sufficient to allow the particles to span the two crack surfaces. A micrograph of the stresswhitened region in the DER 331/Pip/CTB(5)/CTBN8(5) material is shown in Fig. 9. Again, a bimodal particle size distribution is evident. However, the ratio of diameters for the two rubber particle sizes is much larger. Fig. 10 shows the stress-whitened region in the DER 331/Pip/CTBN-8(5)/MBS(5) material. This bimodal system contains the $0.2 \mu \mathrm{m}$ MBS particles which have a tendency to agglomerate. 


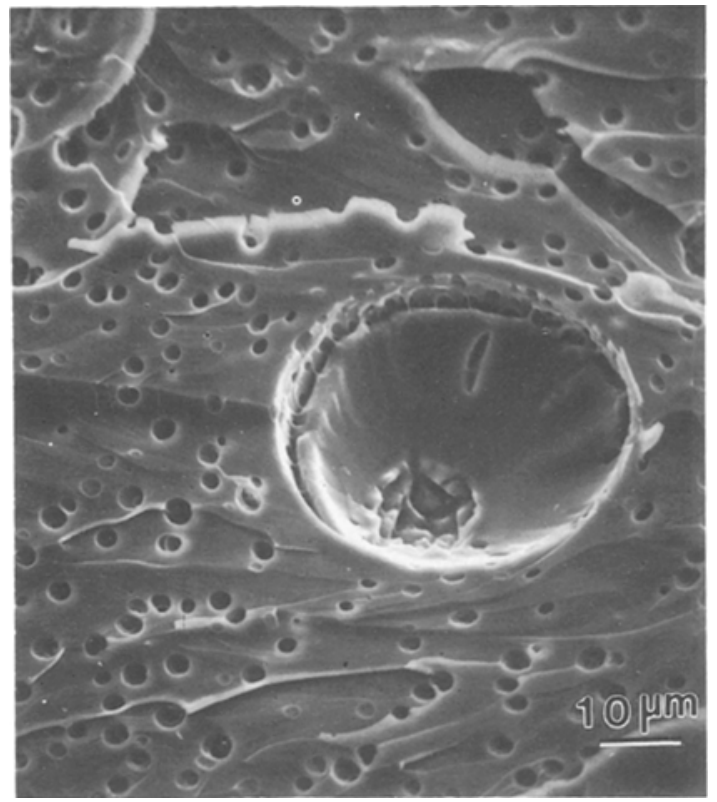

Figure 9 Scanning electron micrograph of the fracture surface of a 3PB specimen of DER 331/Pip/CTB(5)/CTBN-8(5), taken near the precrack arrest region (stress-whitened zone).

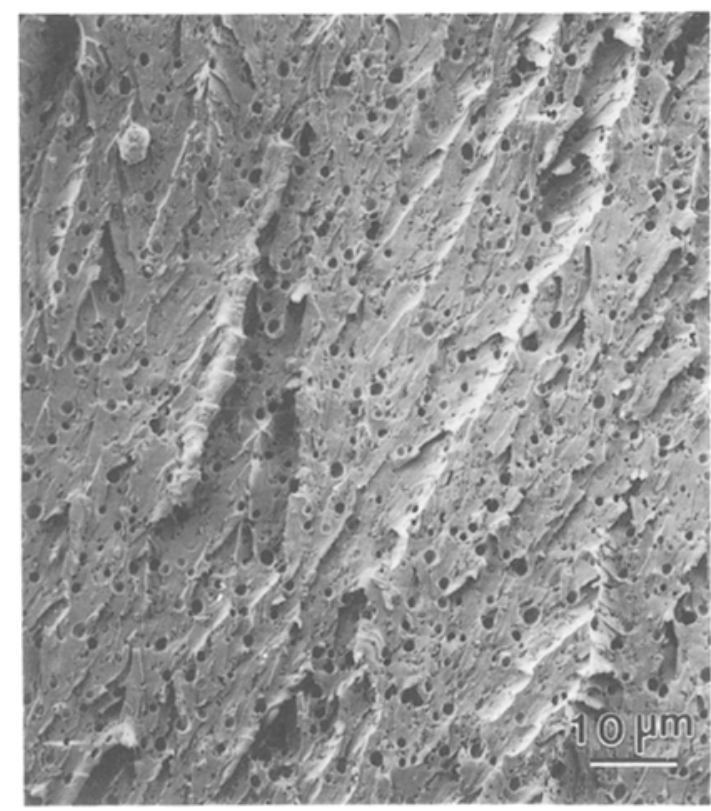

Figure 10 Scanning electron micrograph of the fracture surface of a $3 \mathrm{~PB}$ specimen of DER $331 / \mathrm{Pip} / \mathrm{CTB}(5) / \mathrm{MBS}(5)$, taken near the precrack arrest region (stress-whitened zone).

In summary, SEM shows that the toughening mechanisms for these various rubber-modified epoxies are apparently qualitatively similar. All the particles appear to cavitate internally and the voids have plastically dilated. Evidence presented later will prove that the features of the plastic zones in these toughened epoxies are actually very different, and demonstrates the insensitivity of the SEM technique.

\subsection{Tensile dilatometry}

As mentioned in Section 1, tensile dilatometry is a technique which can be used to monitor the volume change of a material during a uniaxial tensile test.
Typically, there is an initial increase in volume strain due to the Poisson's effect (for small strains). Also typical for homopolymers that tend to yield by shear is the negative slope in the volume strain which begins slightly before the yield point (defined as the stress where $\mathrm{d} \sigma / \mathrm{d} \varepsilon=0$ ). At the yield point, inhomogeneous deformation occurs and necking proceeds immediately as the material in the gauge section strain softens. Homopolymers that tend to craze, such as polystyrene, exhibit a large increase in volume strain due to the inhomogeneous formation of crazes. The volume strain behaviour for two-phase polymer blends can be difficult to interpret because rubber particles can trigger the formation of crazes in those matrices that tend to craze and can cavitate and initiate shear bands in those that shear yield. The mechanisms triggered by the rubber particle are also a function of stress state.

Note that the assumption of additivity between the elastic, shear, and cavitation contributions to the overall volume strain, as proposed by Heikens et al. [24] is not used here to interpret the volume strain curves. Mechanically speaking this assumption is not accurate nor very useful. Shear (deviatoric) strains can be elastic, viscoelastic, and plastic, and they cannot be differentiated without performing unloading experiments. The preceding statement is also true for dilational strains. Moreover, the processes may interact, thus rendering linear additivity invalid. In this work, volume strain measurements for the various rubbermodified epoxies are qualitatively compared to the volume strain results of the neat epoxy in an effort to detect any additional volume strain increases which, in this work, will be proven to arise from the internal cavitation of the rubber particle.

The stress-state sensitivity of the micromechanical deformation mechanisms does limit the usefulness of the tensile dilatometry technique. Therefore examination of deformation mechanisms using a variety of microscopy techniques is necessary to ensure that the mechanisms studied in tensile dilatometry are the same as those at the crack tip. If the mechanisms are the same, then the tensile dilatometry technique is a powerful tool for studying the micromechanical deformations in situ (as opposed to a post-mortem inspection).

Fig. 11 contains a typical plot of stress versus strain together with the volume strain behaviour for the neat epoxy. This neat epoxy shear yields in tension at these strain rates and at room temperature. The volume strain curves are also shown in Fig. 11. The initial portion of this curve is very linear and can be attributed to the Poisson's effect. The volume strain curve appears to go through a maximum as one approaches the yield strain.

Fig. 12 contains a typical plot of stress versus strain together with the volume strain behaviour for the epoxy containing 10 p.h.r. large, $\sim 100 \mu$ m diameter, particles (DER 331/Pip/CTB(10)). This rubber-modified epoxy also yields in tension at these strain rates and at room temperature. The volume strain curves are also shown in Fig. 12. The initial portion of this curve is very linear and again can be attributed to the 


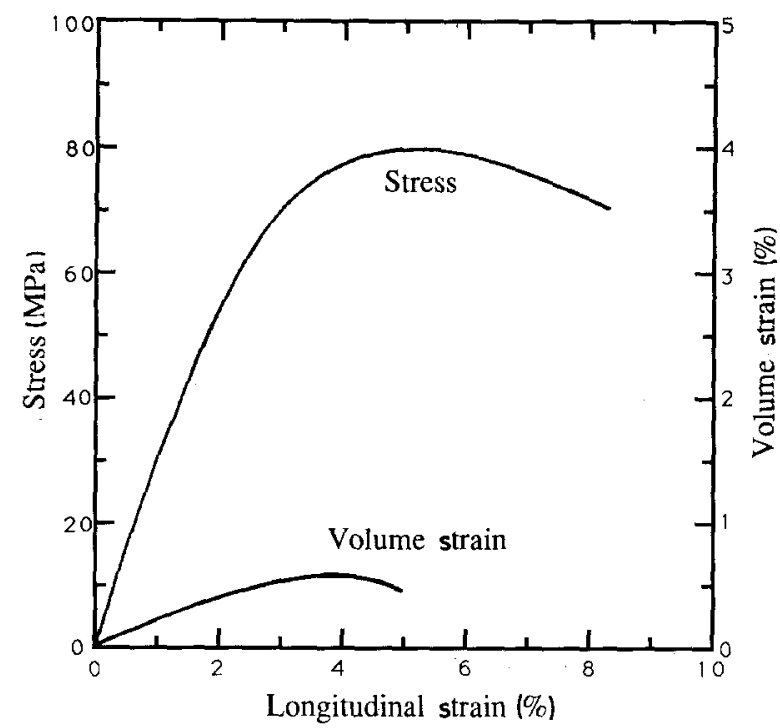

Figure 11 Uniaxial tensile dilatometry results for DER 331/Pip. Temperature $=26 \pm 3^{\circ} \mathrm{C}$, strain rate $=0.007 \mathrm{~s}^{-1}$.

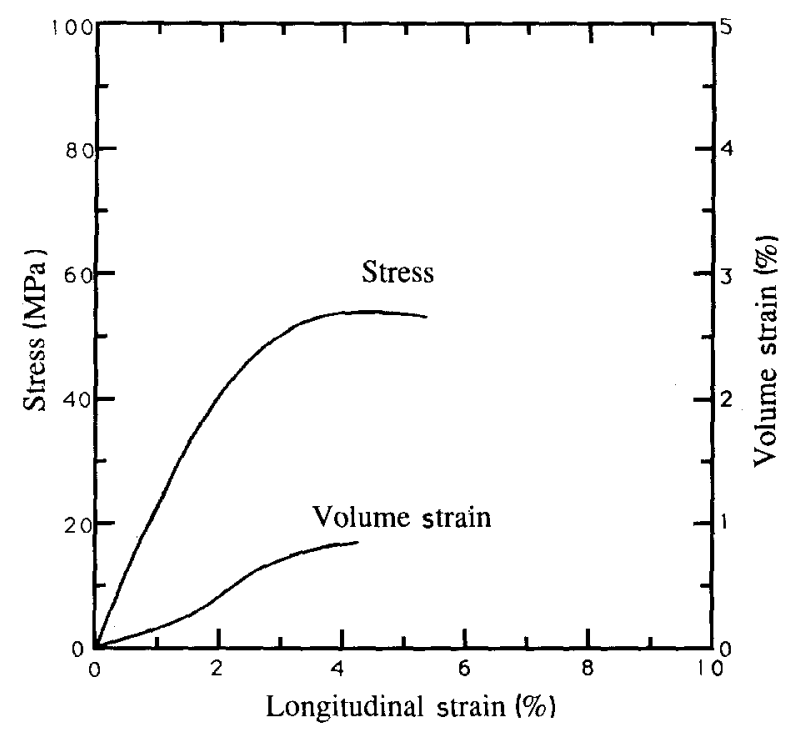

Figure 12 Uniaxial tensile dilatometry results for DER 331/ Pip/CTB(10). Note the additional volume strain occurring at strains greater than $2 \%$. Temperature $=26 \pm 3^{\circ} \mathrm{C}$, strain rate $=0.007 \mathrm{~s}^{-1}$.

Poisson's effect. However, an additional volume strain increase is observed. It will be shown that this additional increase in the volume strain curve can be attributed to the internal cavitation of the rubber particles. It is tempting to reason that the inefficiency in toughening epoxies using this type of rubber is due to poor adhesion or poor cavitational resistance. Subsequent experiments presented in this paper show that this is not the case and that the behaviour of these relatively large rubber particles at the crack tip is very different than that of the smaller particles.

Fig. 13 contains a typical plot of stress versus strain together with the volume strain behaviour for the epoxy containing 10 p.h.r. $2.0 \mu \mathrm{m}$ particles (DER $331 / \mathrm{Pip} / \mathrm{CTBN}-8(10))$ and for the epoxy containing 10 p.h.r. $0.2 \mu \mathrm{m}$ particles (DER 331/Pip/MBS(10)). These rubber-modified epoxies also yield in tension at these strain rates and at this temperature $\left(26^{\circ} \mathrm{C}\right)$. The initial portion of the volume strain is attributed to the now familiar Poisson's effect. Unlike the results for the

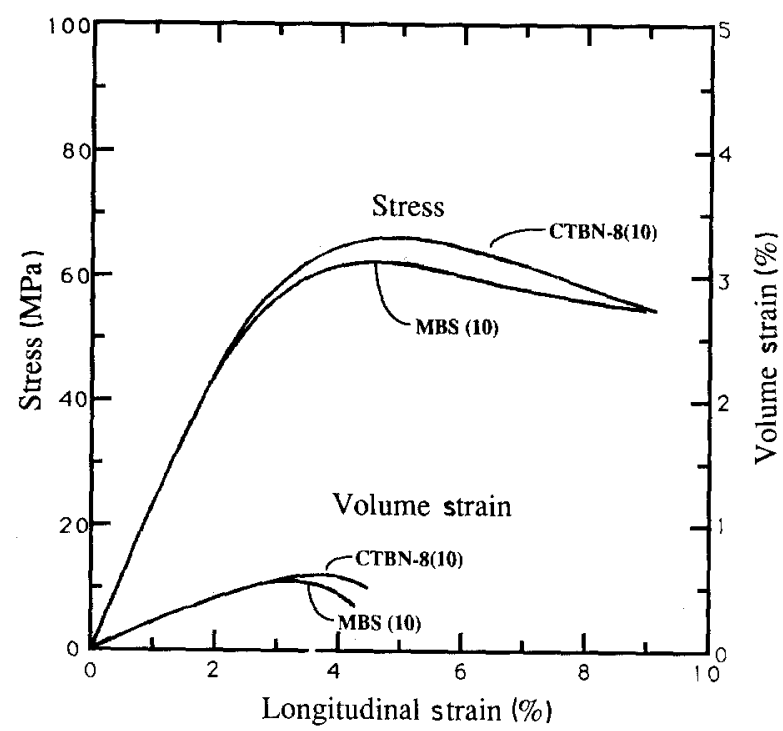

Figure 13 Uniaxial tensile dilatometry results for DER 331/Pip/ CTBN-8(10) and DER 331/Pip/MBS(10). Note the absence of any additional volume strain (as compared to Fig. 12). Temperature $=26 \pm 3{ }^{\circ} \mathrm{C}$, strain rate $=0.007 \mathrm{~s}^{-1}$.

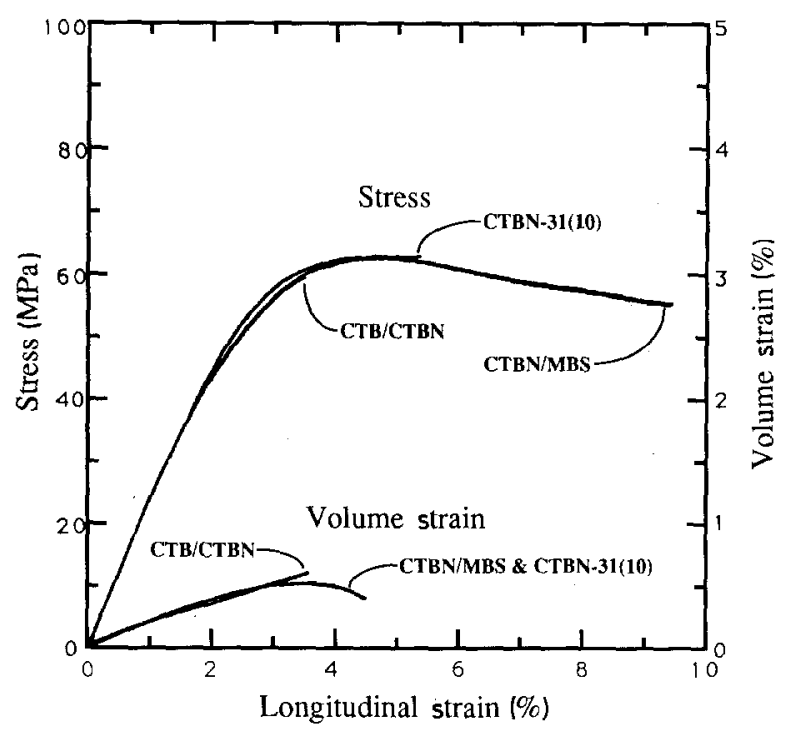

Figure 14 Uniaxial tensile dilatometry results for several rubbermodified epoxies with bimodal particle size distributions. Note the absence of any additional volume strain (as compared to Fig. 12). Temperature $=26 \pm 3^{\circ} \mathrm{C}$, strain rate $=0.007 \mathrm{~s}^{-1}$.

large particles, these volume strain curves are very similar to that of the neat epoxy. On the basis of this evidence, one might conclude that the cavitational resistance of this type of rubber modifier is greater than that for the CTB-162 particles. An important observation is the occurrence of stress whitening in the necked region of the tensile specimen which suggests that these particles do cavitate when the hydrostatic tensile component is increased. Evidence for cavitation of these rubber particles at a crack tip has been presented in Section 3.3 and additional evidence will be presented in Section 3.6.

Fig. 14 contains a typical plot of stress versus strain together with the volume strain behaviour for the epoxies containing 10 p.h.r. rubber with a bimodal distribution of particle size (DER 331/Pip/CTB(5)/ CTBN-8(5); DER 331/Pip/CTBN-31(10); DER 331/ 
Pip/CTBN-8(5)/MBS(5). The uniaxial tensile behaviour is not unlike the unimodally distributed, rubbermodified epoxies. Despite the similarity of the tensile behaviour, we show in later sections that the plastic zones in these materials can be very different from each other.

In summary, the tensile dilatometry technique can differentiate the cavitational resistance of the CTBmodified epoxies from other rubber-modified epoxies studied in this work. However, this apparent reduced cavitational resistance is not the reason why these particles are rather inefficient in terms of producing a toughening effect. Section 3.6 clearly identifies the mechanism that provides this modest toughening effect.

\subsection{Sub-surface analysis of tensile specimens}

Strain and orientation-free polymeric glasses are optically isotropic, i.e. refract light equally in all directions. Plastically deformed polymeric glasses are not optically isotropic and therefore are birefringent. Birefringence can be used to detect residual elastic and plastic strains in polymeric glasses. Optically isotropic, stressfree materials will appear dark when viewed between completely crossed polarizers whereas deformed material which is birefringent will transmit part of the light. Quarter wave plates may be inserted in the light path to shift the colour of the image and to provide isometric fringes. A quarter wave plate is often used in this work and the resulting black and white micrographs will show the plastically deformed regions as dark areas.

In addition to using crossed-polarized light, brightfield imaging is used to examine individual particles (if the diameters are greater than $1 \mu \mathrm{m}$ ) and is useful in examining stress-whitened zones. Note that the cavitated particles scatter light and provide the stresswhitening effect in reflected light; however, the scattering of light in transmission microscopy results in a dark image.

Fig. 15 contains an optical micrograph of a thin section taken parallel to the tensile direction and near the inclined neck section of a neat epoxy specimen. The specimen has shear yielded and fracture had occurred in this necked region. The section is viewed using crossed-polarized light without a quarter wave plate. A bright but diffuse shear yielded zone is observed. No shear bands are detected at this magnification. The observation of shear bands is expected because polymeric glasses intrinsically strain soften and hence can form inhomogeneities that nucleate shear bands [25]. There are some shear bands near the edges of the specimen; but these bands are a result of stress concentrations at the edges which were not removed by polishing.

Fig. 16 contains an optical micrograph of a thin section taken parallel to the tensile direction and near the inclined necked section of a rubber-modified epoxy tensile specimen (modified with 10 p.h.r. CTBN-31) The section is again viewed using crossedpolarized light. Shear bands are evident as bright cross patterns and their formation is due to the local stress

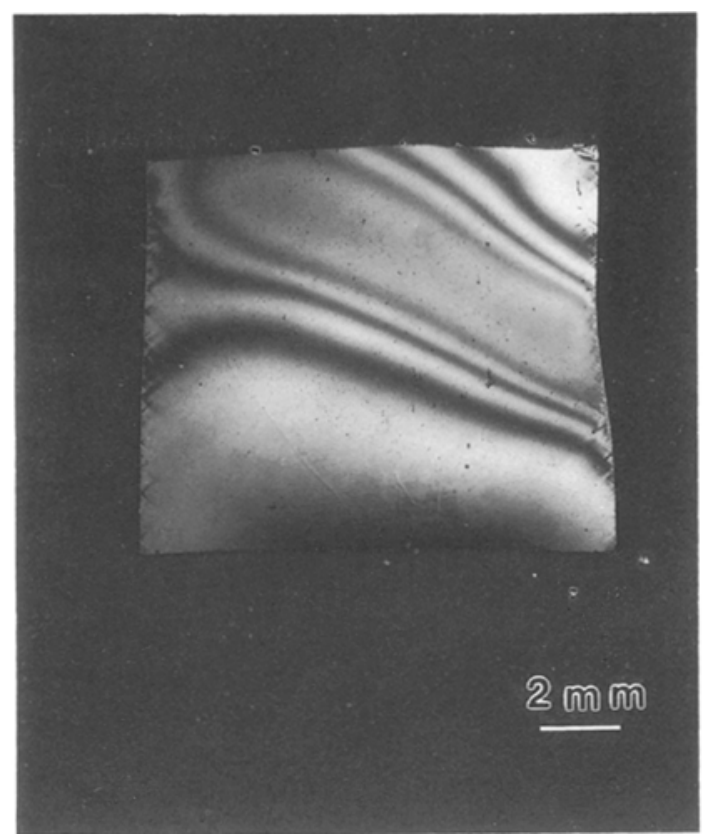

Figure 15 Optical micrograph of a thin section taken parallel to the tensile direction and near the necked region of a DER 331/Pip tensile specimen. This section is viewed using crossed polarized light.

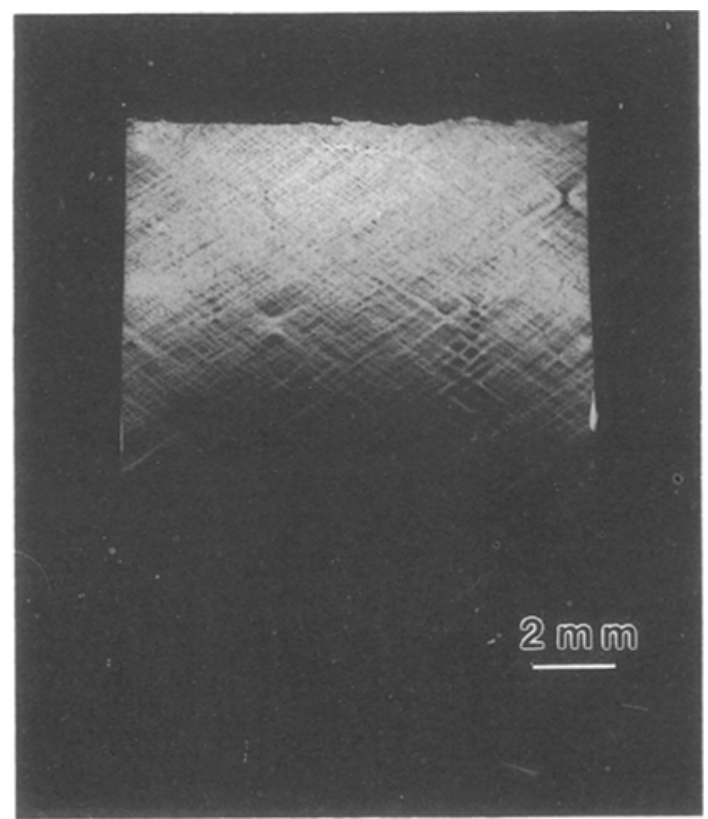

Figure 16 Optical micrograph of a thin section taken parallel to the tensile direction and near the necked region of a DER 331/Pip/ CTBN-31(10) tensile specimen. This section is viewed using crossed polarized light.

concentrations of the rubber particles that modify the stress state to the appropriate value for plane-strain deformation. Observation of these shear bands is typical for those epoxies in this work modified with rubber particles greater than $1 \mu \mathrm{m}$ diameter. Individual shear bands from rubber particles less than $1 \mu \mathrm{m}$ cannot be observed (due to the resolution of the optics) and only a diffuse sheared region is observed.

Fig. 17 is an optical micrograph which was taken using crossed-polarized light and a quarter wave plate at a higher magnification of a thin section taken from 


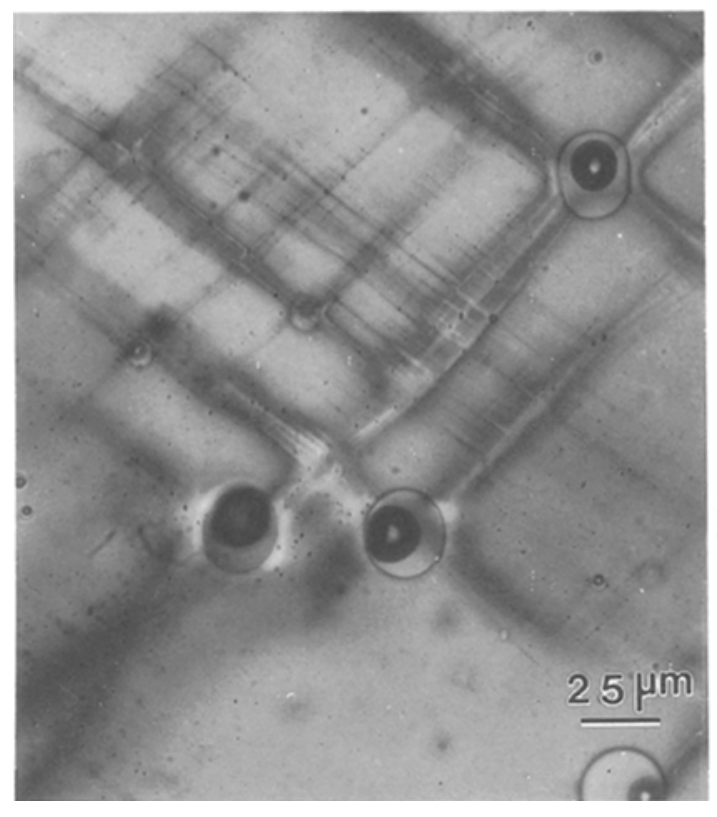

Figure 17 Optical micrograph of a thin section taken parallel to the tensile direction and near the necked region of a DER 331/Pip/ $\mathrm{CTB}(10)$ tensile specimen. A quarter wave plate has been inserted in the path of the optical wave train to facilitate the observation of the shear bands and the cavitated rubber particles.

a deformed tensile specimen of the DER 331/Pip/ CTB(10) material. It clearly illustrates the internal cavitation of the rubber particles which is seen as thick dark circles within the rubber particles. Therefore, the additional increase in the volume strain curve is due to the internal cavitation of the rubber particles and the concomitant dilation of the surrounding epoxy matrix. A similiar observation has been reported in a previous work [6]. The majority of shear bands occur at angles of $\sim 52^{\circ}$ from the major principal axis; however, this angle can be as high as $90^{\circ}$ for those particles that are close enough for interaction (not shown). Interaction between particles appears to be necessary for shear banding because particles with isolated shear bands are not observed.

Fig. 18 contains an optical micrograph of a thin section taken parallel to the tensile direction and near. the inclined neck section of a CTBN-8(10)-modified epoxy tensile specimen. Fig. 19 reveals features identical to the CTB-modified epoxy, i.e. cavitated particles and shear bands between particles. The interparticle distance is much shorter for these particles due to the smaller particle size and therefore, many planes containing rubber particles are in focus.

Fig. 19 contains an optical micrograph of a thin section taken parallel to the tensile direction and near the inclined neck section of a CTBN-31(10)-modified epoxy tensile specimen. The section is viewed using crossed-polarized light and a quarter wave plate. Note that the large particle in the centre of the micrograph has bands emerging at angles other than $45^{\circ}$ and a simple pattern of " $\mathrm{X}$ "s is not observed. This complicated pattern is due to the interaction of the large particle with many of its smaller neighbours. The stress field overiap of the large particles induces the cavitation and shear banding of the smaller particles. Shear bands are formed due to the local stress concen-

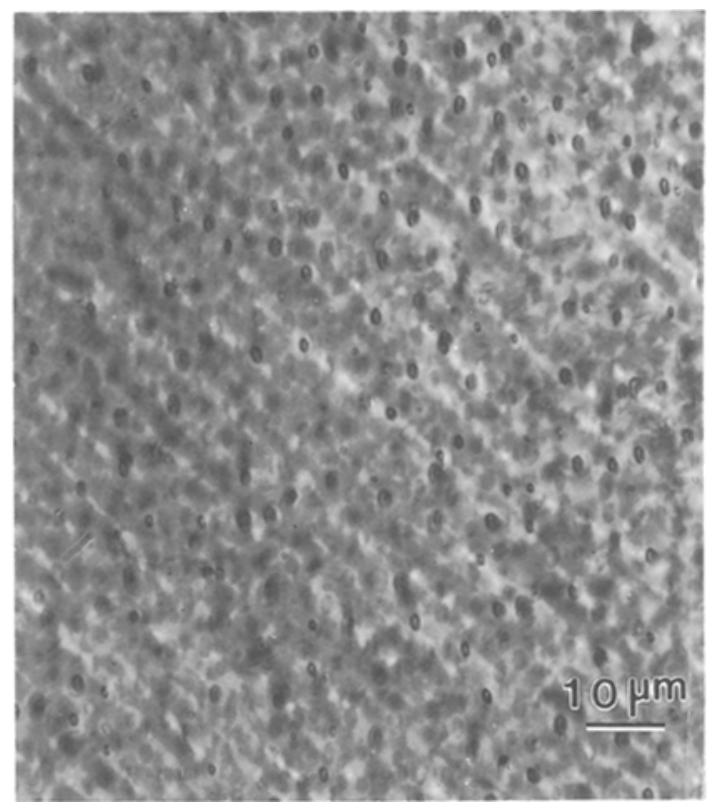

Figure 18 Optical micrograph of a thin section taken parallel to the tensile direction and near the necked region of a DER 331/Pip/ CTBN-8(10) tensile specimen. This section is viewed using crossed polarized light and a quarter wave plate

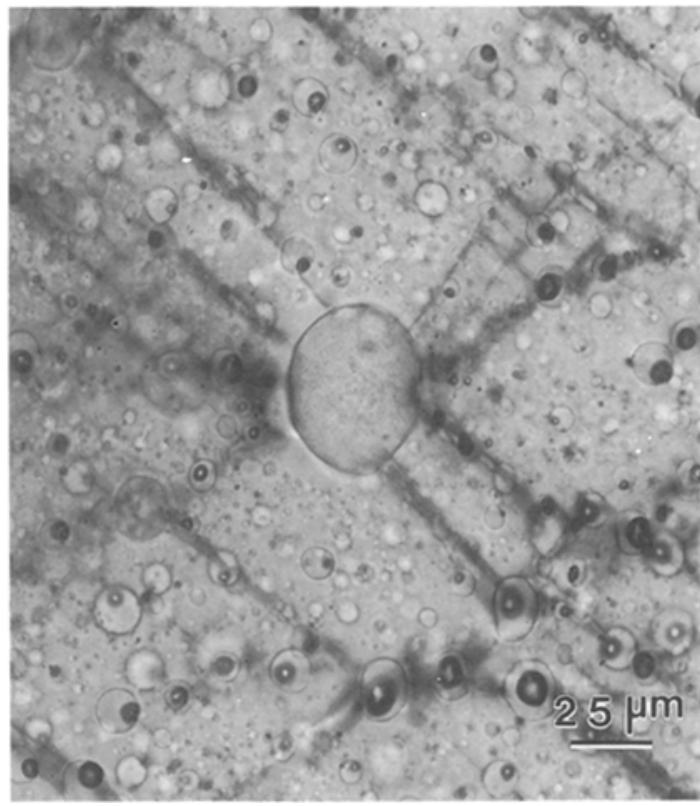

Figure 19 Same as Fig. 16 but a thinner section viewed at a higher magnification. Note the multiple particle interactions between the large particle and several smaller, neighbouring particles.

trations of the rubber particles which raise the stress to the appropriate value for shear yielding. The existence of these cavities explains the observed stress whitening seen in the necked region of the tensile specimen.

Fig. 20 contains an optical micrograph of a thin section taken parallel to the tensile direction and near the inclined necked section of a CTB(5)/CTBN-8(5)modified epoxy tensile specimen. This micrograph was taken using crossed polarized light and a quarter wave plate. Fig. 20 reveals that the stress field overlap between two very large particles induces the cavitation of several small particles in the vicinity, whereas those 


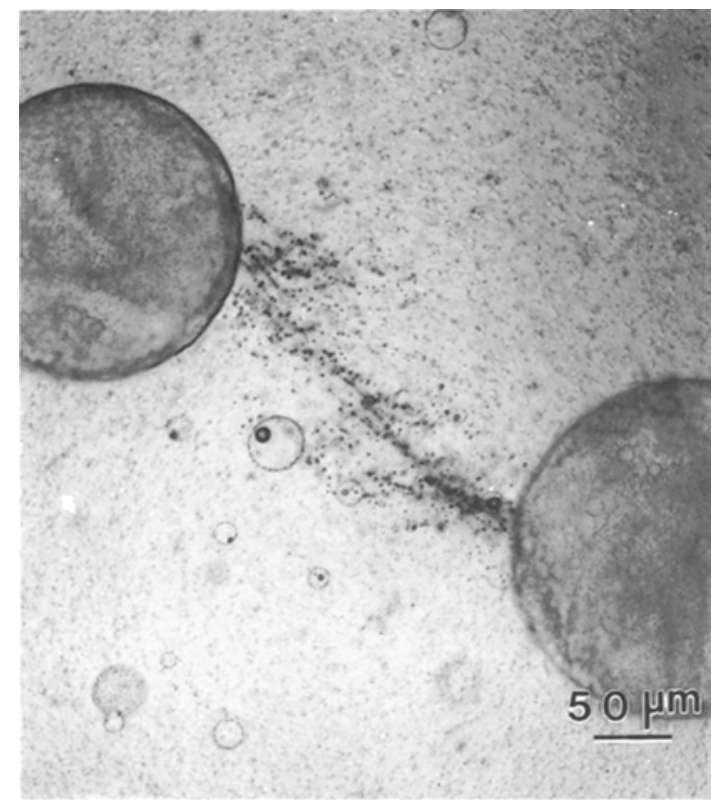

Figure 20 Optical micrograph of a thin section taken parallel to the tensile direction and near the necked region of a DER 331/Pip/ CTB(5)/CTBN-8(5) tensile specimen. Note that the interactions between the two large particles are highlighted by the paths of smaller particles that have cavitated

small particles not near the large ones have not cavitated. This micrograph clearly shows the difference in the nature of the particle particle interactions as the difference in size of the two types of rubber particle is increased.

\subsection{Sub-surface analysis of the DN-4PB specimens}

Since the early conception of linear elastic fracture mechanics (LEFM) it has been recognized [26] that the measured fracture toughness is not simply equivalent to the energy required to create two new surfaces but is dominated by the plastic work term, even for fairly brittle materials. As the fracture toughness increases the size of the plastic zone also increases. For very ductile materials (in terms of fracture toughness) the plastic zone may be so large that the stress field at the crack tip can no longer be described using the LEFM approach and the fracture toughness must now be quantified using an elastic-plastic fracture mechanics approach. Because the fracture toughness is due to the formation of a plastic zone then an examination of this zone should reveal the micromechanical mechanism(s) responsible for the toughening effect. Optical microscopy is used to examine the plastic zones at crack tips and these matured zones have been obtained using a double-notched four-point bending method.

Fig. 21 contains an optical micrograph of a thin section taken in the mid-plane and near the crack tip of a neat epoxy specimen which had been tested using the double-notched four-point bending method. This micrograph contains the crack which was unloaded after the propagation of the other crack. This micrograph reveals that there is very little plastic damage in the vicinity of the crack tip. The absence of a plastic

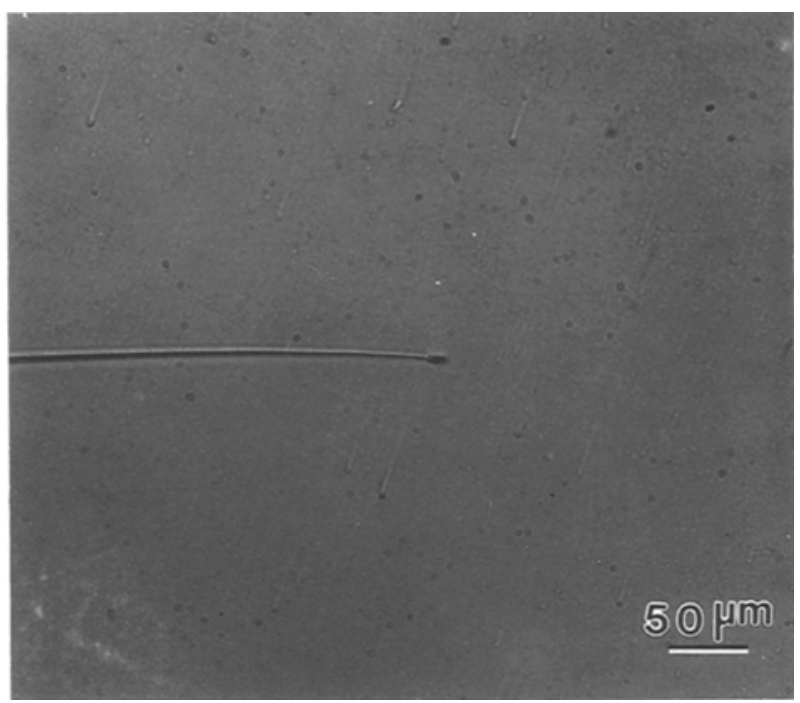

Figure 21 Optical micrograph of a thin section taken mid-plane and near the crack tip of a DN-4PB sample of a DER 331/Pip, viewed in bright field. Note the abscence of a damage zone.

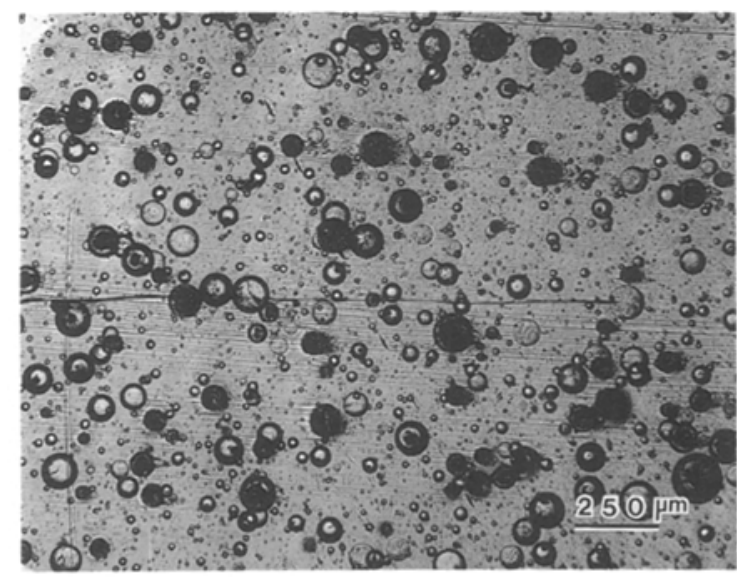

Figure 22 Optical micrograph of a thin section taken mid-plane and near the crack tip of a DN-4PB sample of a DER 331/Pip/ $\mathrm{CTB}(10)$, viewed in bright field. Note the absence of a damage zone.

zone correlates well with the low critical stress intensity value measured.

Fig. 22 contains an optical micrograph of a thin section taken in the mid-plane and near the crack tip for an epoxy modified with 10 p.h.r. CTB (large particles). Several features are noteworthy. There is very little evidence of a birefringent zone at the crack tip. Therefore, the existence of a shear plastic zone is not supported. This observation correlates well to the lack of significant toughening measured for this material; however, the fracture toughness is twice that of the neat epoxy. Fig. 23 is a micrograph taken at a higher magnification of a similar crack which has been wedged opened to clearly reveal the presence of bridging particles. The observation of particle bridging may explain the modest increase in fracture toughness for this material $[13,27]$. The dark particles observed in these micrographs (Figs 28 and 29) have not cavitated; rather, they have been damaged by polishing.

Fig. 24 is an optical micrograph of a thin section taken in the mid-plane and near the crack tip for an epoxy modified with 10 p.h.r. CTBN-8. The nature of 


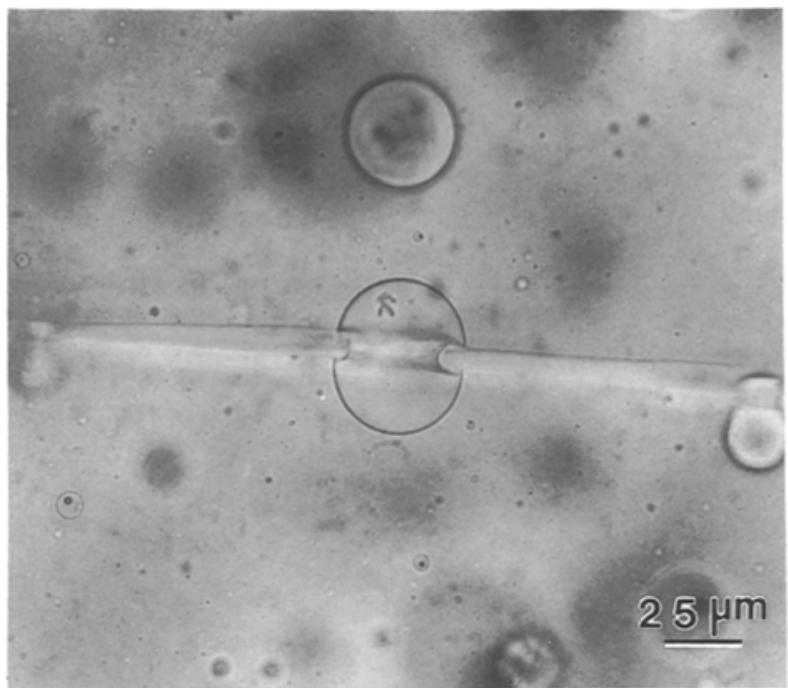

Figure 23 Same as Fig. 28 but at a higher magnification and the crack was wedged opened. Note the presence of bridging particles.

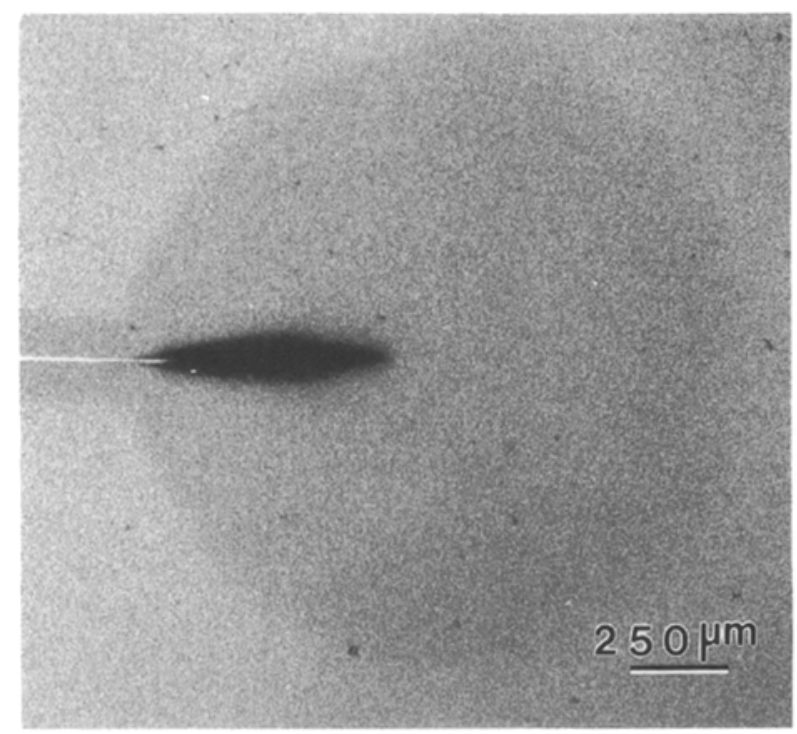

Figure 24 Optical micrograph of a thin section taken mid-plane and near the crack tip of a DN-4PB sample of a DER $331 / \mathrm{Pip} / \mathrm{CTBN}-8(10)$, viewed in bright field. Note the presence of a circular zone which contains slightly cavitated particles and a darker elliptical zone that contains highly cavitated particles embedded in a plastically deformed matrix.

the plastic zone is very different from that of the neat epoxy and the CTB-modified epoxy. There is a grey circular zone a few millimetres in diameter, surrounding the crack tip. In close proximity to the crack tip there is a smaller, darker, elliptical region which is the stress-whitened zone in reflected light. The outer, circular zone contains only internally cavitated particles which suggests that the particles must cavitate at a relatively low stress. The inner, darker zone which surrounds the crack tip is comprised of highly plastically dilated cavities and shear bands as shown in Fig. 25.

Fig. 26 is an optical micrograph of a thin section taken in the mid-plane and near the crack tip for an epoxy modified with 10 p.h.r. MBS. The nature of the plastic zone is again very unique to this particular

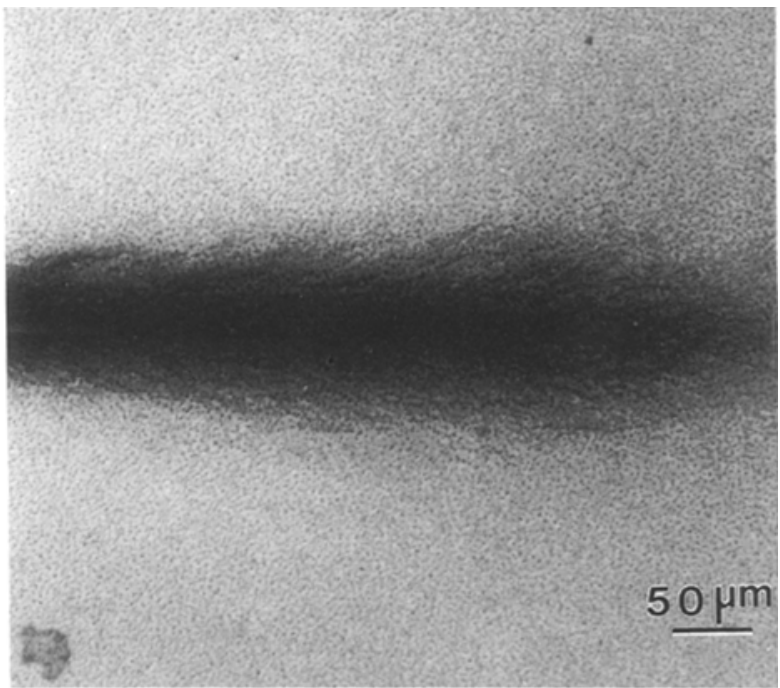

Figure 25 Same as Fig. 24 but a thinner section of the plastic zone taken at a higher magnification.

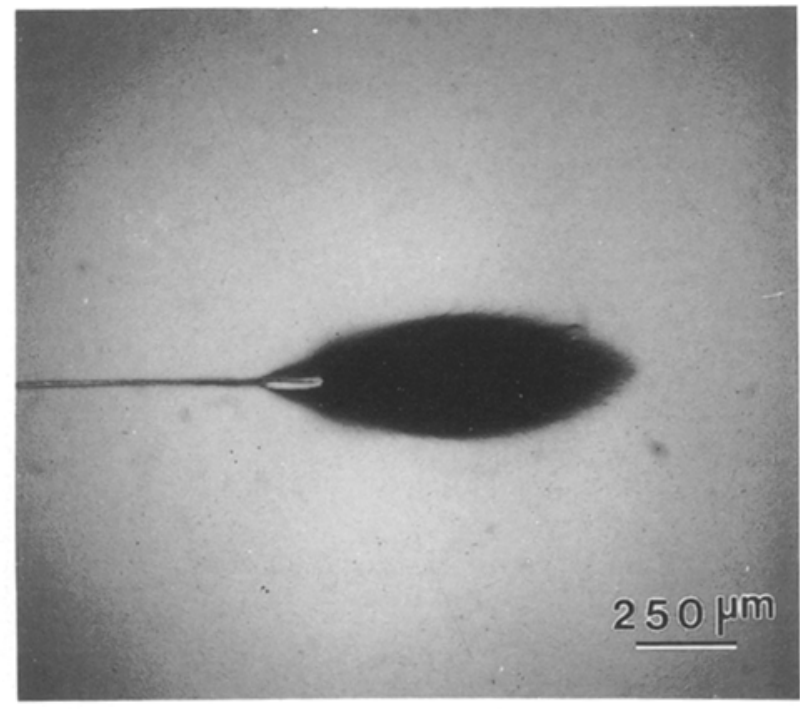

Figure 26 Optical micrograph of a thin section taken mid-plane and near the crack tip of a DN-4PB sample of a DER 331/Pip/MBS (10), viewed in bright field. Note the increase in the size of the plastic zone and the change in shape.

rubber-modified epoxy. The absence of a circular cavitation zone suggests that the cavitational stress is higher for this MBS modifier than for the CTBN-8 rubber. The relatively large stress-whitened zone correlates well with the increase in fracture toughness (note: the size of the plastic zones depends on the difference in crack lengths for the two nearly identical cracks.) The stress-whitened zone is birefringent as shown by the large, uniformly grey zone around the crack tip in Fig. 27, which suggests the presence of shear bands (which are too small to be resolved). Other features worth noting are the "fingers" seen at the outer edges of the plastic zone which may be related to the agglomeration seen using SEM, and the existence of a transparent region at the beginning of the plastic zone. This transparent region may be attributed to a heavily sheared region which effectively closes up the voided rubber particles [21]. 


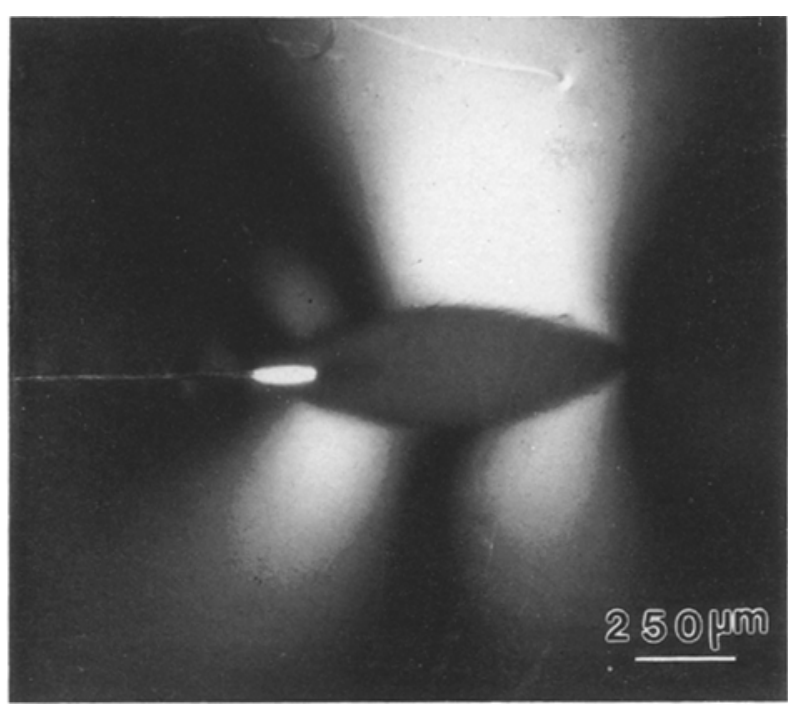

Figure 27 Same as Fig. 32 but viewed using crossed polarized light. Note that the damage zone is birefringent, indicating that the matrix has shear yielded.

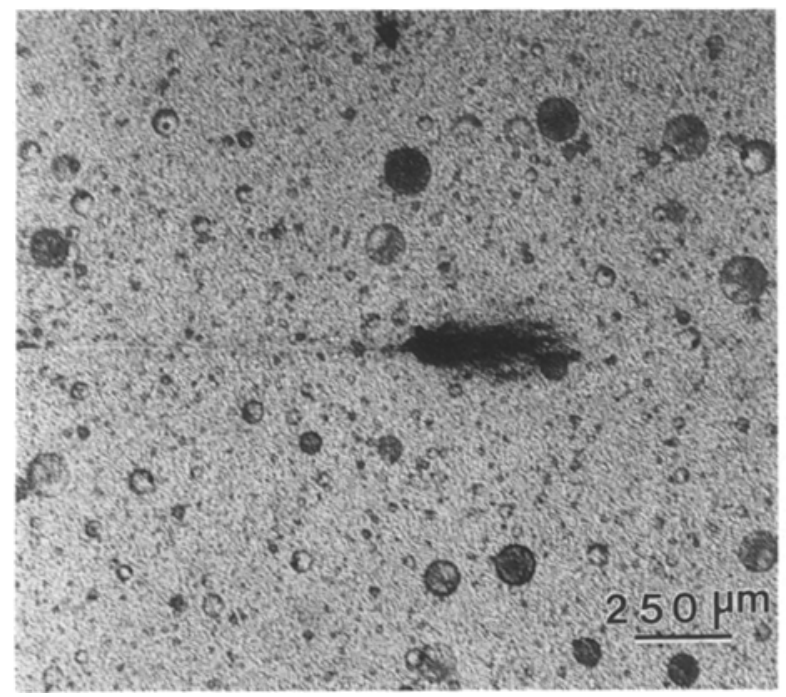

Figure 28 Optical micrograph of a thin section taken mid-plane and near the crack tip of a DN-4PB sample of a DER 331/Pip/ CTB(5)/CTBN-8(5), viewed in bright field.

Fig. 28 is an optical micrograph of a thin section taken in the mid-plane and near the crack tip for an epoxy modified with 5 p.h.r. CTB and 5 p.h.r. CTBN8. There is a stress-whitened zone at the crack tip which is birefringent under crossed polarized light. The existence of a plastic zone correlates well with the fracture toughness measured for this material. Fig. 29 is a micrograph taken at a higher magnification. A rubber particle spanning the crack is clearly seen. Therefore, this material displays three of the toughening mechanisms: bridging, shear banding, and plastic dilation. The bridging mechanism is exhibited only by the larger particles.

Fig. 30 contains an optical micrograph of a thin section taken in the mid-plane and near the crack tip for an epoxy modified with 10 p.h.r. CTBN-31. Again, no circular cavitational zone is observed. Also, the stress-whitened zone appears to have a fish-bone type

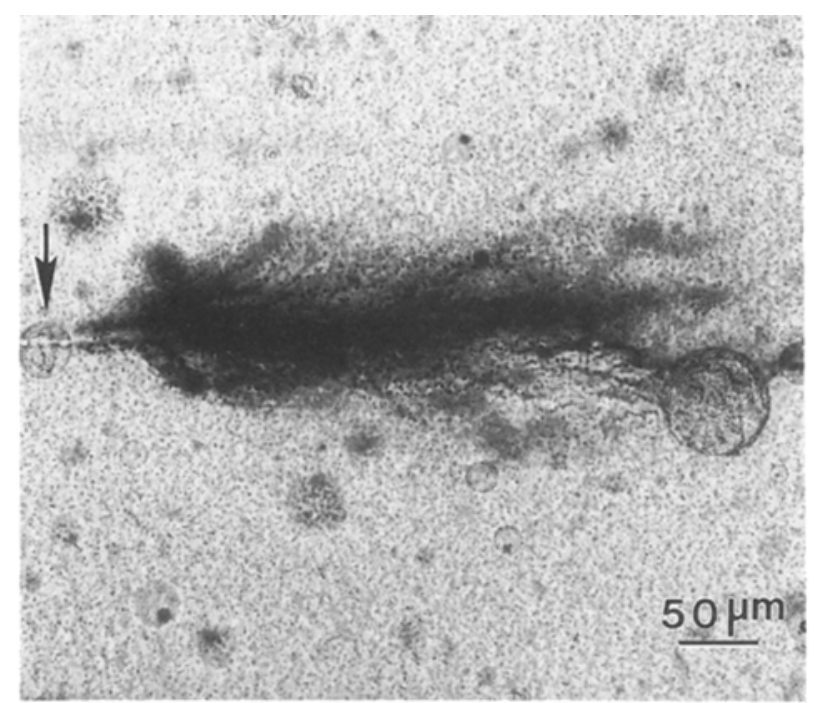

Figure 29 Same as Fig. 28 but at a higher magnification. Note the presence of a bridging particle as well as an elliptical damage zone.

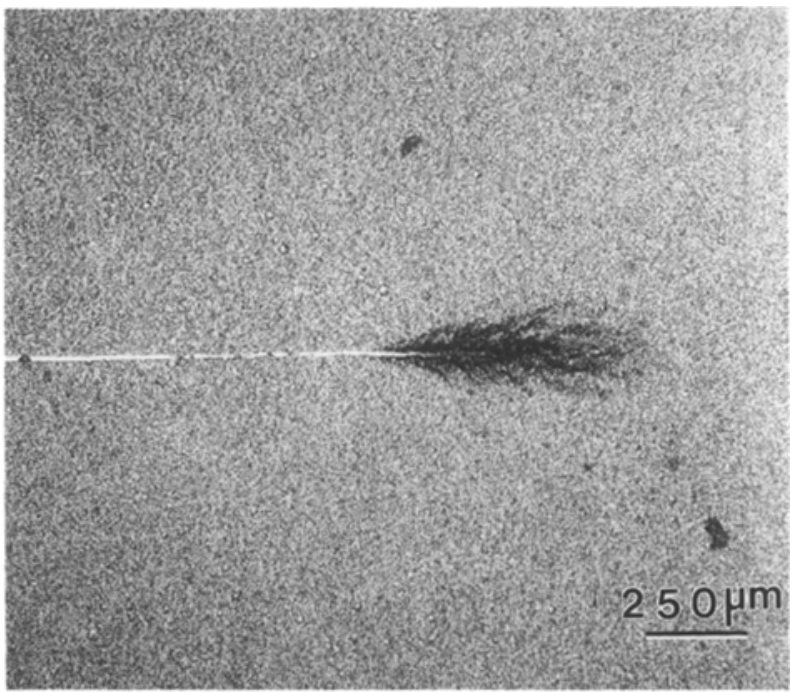

Figure 30 Optical micrograph of a thin section taken mid-plane and near the crack tip of a DN-4PB sample of a DER 331/Pip/ CTBN-31(10), viewed in bright field.

shape which is a feature unique to this system. Fig. 31 is a micrograph taken at a higher magnification. Inspection of this micrograph reveals the influence of the larger particle ( $\sim 20 \mu \mathrm{m}$ diameter). The large particles tend to deflect the crack tip (a mechanism for toughening $[28,29]$ ) and enhance the cavitation of the smaller particles in the vicinity of the equator of the larger particles (see Fig. 32.). Also, similar to that shown in Fig. 29, these large particles bridge the two crack surfaces. Unfortunately, even with the variety of mechanisms occurring at the crack tip of this material, the resulting toughness is no greater than that of the CTBN-8 modified epoxy.

Fig. 33 is an optical micrograph of a thin section taken in the mid-plane and near the crack tip for an epoxy modified with 5 p.h.r. CTBN-8 and 5 p.h.r. MBS. Again, this plastic zone is rather unique. There is a cavitational zone (not visible in this micrograph) 


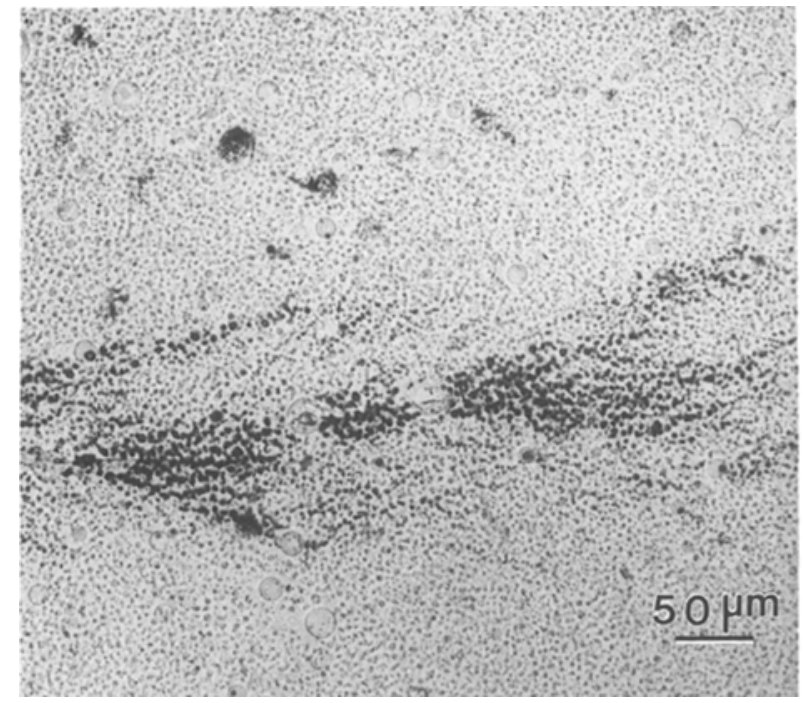

Figure 31 Same as Fig. 30 but at higher magnification. Note that the crack path has been deflected due to the presence of the relatively large particles.

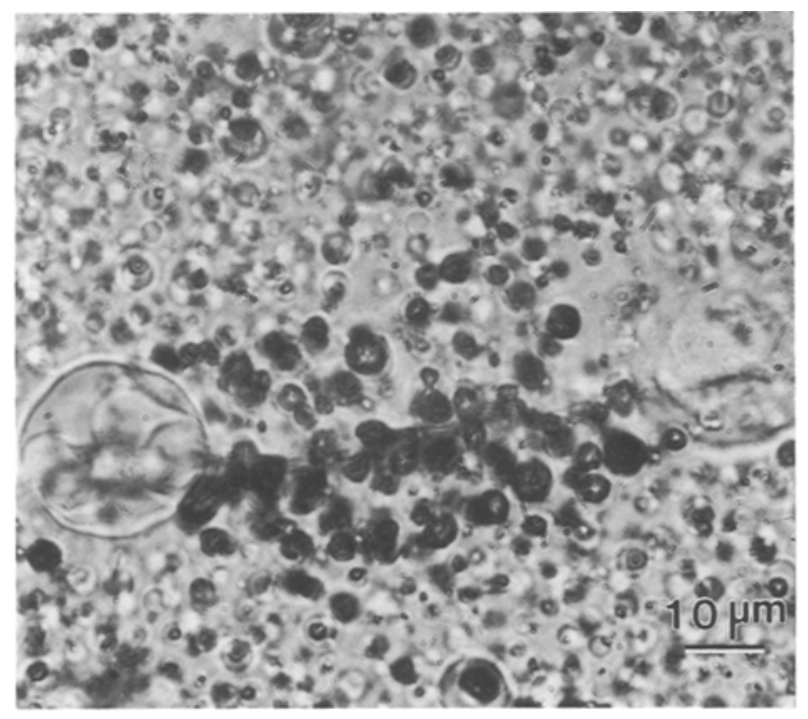

Figure 32 Same as Fig. 31 but at an even higher magnification. Note that the smaller particles near the crack surface, and between the two large particles, are intensely cavitated.

which surrounds the crack tip. It is similar to the circular zone observed for the 10 p.h.r. CTBN-8 modified epoxy. The stress-whitened zone, which is birefringent under crossed polarized light, is less elliptical in shape than for the other rubber-modified epoxies studied in this investigation. The prominent toughening mechanisms appear to be plastic dilatation and shear banding. The resulting toughness is lower than the 10 p.h.r. MBS-modified epoxy which further suggests that the MBS particles are better than the CTBN-8 particles in providing a toughening effect.

\section{Discussion}

4.1. The effect of rubber particle size on the improvement of the fracture toughness

Table II suggests that fracture toughness increases with decreasing particle size. These results are in direct

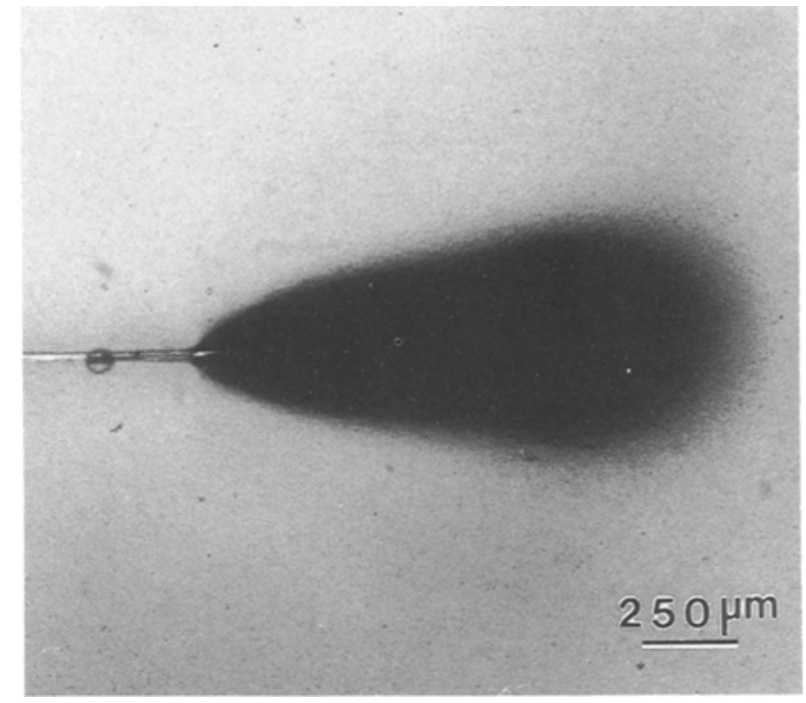

Figure 33 Optical micrograph of a thin section taken mid-plane and near the crack tip of a DN-4PB sample of a DER 331/Pip/ CTBN-8(5)/MBS(5), viewed in bright field. Note the change in shape of the plastic zone.

contradiction with the rubber particle stretching and tearing model which predicts that toughness should increase with increasing particle size [27] and is consistent, on the surface, with the notion of a critical interparticle distant needed for interparticle interactions [14]. However, this conclusion must be treated with caution because, in changing the particle size, the rubber particle properties are also varied. More specifically, the cavitational resistance of the various types of rubbers has been shown to be an uncontrolled variable. Boyce et al. [30] have shown that for hot isostatic pressing the particle microstructure controls its compliance, which is thought to govern its efficiency in toughening polymers that tend to craze. Recently, Borggreve et al. [31, 32] have shown that rubber particle properties and voiding are crucial contributors to the toughness of rubber-modified nylon and are perhaps more important than the interparticle distance.

\subsection{An empirical criterion for bridging particles}

Large particles have been shown to span the two crack surfaces, whereas small particles cavitate in a process zone in the vicinity of the crack tip. One question that immediately arises is: what size particles should be considered large and what size particles should be considered small. The following rationale is proposed. In order for a particle to cavitate it must be embedded in a stress field with a stress magnitude reaching a critical value extending over a certain spatial scale. Therefore, a scaling concept should be used for the size of this "suitable" zone. Empirically the size of this "suitable". zone is assumed to be equivalent to the "formal plastic zone" proposed by Irwin [33]. Irwin stated that the formal plastic zone size may be estimated, for the plane strain case, by

$$
r_{\mathrm{p}}=1 / 6 \pi\left(K_{\mathrm{IC}} / \sigma_{\mathrm{y}}\right)^{2}
$$


TABLE II Fracture toughness values of some rubber-modified epoxies

\begin{tabular}{llcr}
\hline Formulation & $\begin{array}{l}\text { Particle size } \\
(\mu \mathrm{m})\end{array}$ & $\begin{array}{l}K_{\mathrm{IC}} \\
\left(\mathrm{MPa} \mathrm{m}^{\mathrm{1} / 2}\right)\end{array}$ & $\begin{array}{l}G_{\mathrm{IC}} \\
\left(\mathrm{J} \mathrm{m}^{-2}\right)\end{array}$ \\
\hline DGEBA/PIP & 0 (neat resin) & 0.80 & 180 \\
DGEBA/PIP/CTB-162 & $\leqslant 200$ & 1.10 & 410 \\
DGEBA/PIP/CTB/CTBN & $1-2,100-200$ & 1.95 & 1275 \\
DGEBA/PIP/CTBN-8 & $1-2$ & 2.10 & 1440 \\
DGEBA/PIP/CTBN-31 & $1-2,10-20$ & 2.00 & 1300 \\
DGEBA/PIP/MBS & $\sim 0.2$ & 2.90 & 2725 \\
DGEBA/PIP/MBS/CTBN & $0.2,1-2$ & 2.75 & 2465 \\
\hline
\end{tabular}

Note: all rubber-modified epoxies contain 10 p.h.r. rubber.

where $r_{\mathrm{p}}$ is the radius of the plastic zone, $K_{\mathrm{IC}}$ is the critical stress intensity factor, and $\sigma_{y}$ is the yield stress.

For this calculation we will take the two latter quantities to be those of the neat epoxy matrix to be toughened. For the piperidine-cured epoxy, the resultant plastic zone size would be approximately $6 \mu \mathrm{m}$. If our rationale is correct, then particles larger than $6 \mu \mathrm{m}$ would not cavitate even if they where capable of it. Our experimental observations reveal that particles as sinall as $8 \mu \mathrm{m}$ act as bridging particles. Therefore, this rather empirical approach appears to give the correct upper bound as far as the particle size for bridging is concerned. Particles smaller than this size should cavitate and promote shear yielding.

A DN-4PB test using a $10 \mathrm{mil}(1 \mathrm{mil} \simeq 25.4 \mu \mathrm{m})$ radius $\mathrm{V}$-notch was performed to provide further evidence for this critical process zone size concept. The use of a blunt notch raises the apparent fracture toughness to $4.7 \mathrm{MPa} \mathrm{m}^{1 / 2}$ and, more importantly increases the size of the plastic zone. Now, even the very large particles in the epoxy modified with 10 p.h.r. CTB-162 particles should cavitate in front of this notch because the plastic zone is now larger than the average particle diameter. Fig. 34 is an optical micrograph taken using reflected light of the plastic zone in front of a $10 \mathrm{mil}$ radius notch for the epoxy modified with 10 p.h.r. CTB. Indeed, these same particles which act as bridging particles at a crack tip now cavitate in front of the notch tip. Increasing the process zone size exposes these relatively large particles to the hydrostatic tension which cause them to cavitate and are able to enhance shear band formation. In other words, the mechanism is now identical to those rubber-toughened epoxies containing relatively small rubber particles. Thus, we contend that the role played by the toughening particle is scaled to the size of the inherent process zone of the neat epoxy matrix.

One more example of this scaling concept between the size of the process zone and the size of the rubber particle can be illustrated using a highly cross-linked epoxy. In a recent paper [12], a highly cross-linked epoxy (DER 332/DDS) was modified with 10 p.h.r. Hycar $^{\oplus}$ CTBN $1300 \times 13$ liquid rubber resin. This rubber modification resulted in rubber particles with an average diameter of $\sim 5 \mu \mathrm{m}$. No plastic zone was detected using optical microscopy and the increase in fracture toughness due to rubber modification was only $80 \mathrm{~J} \mathrm{~m}^{-2}$. Therefore we surmise that rubber particle bridging is the probable toughening mechanism

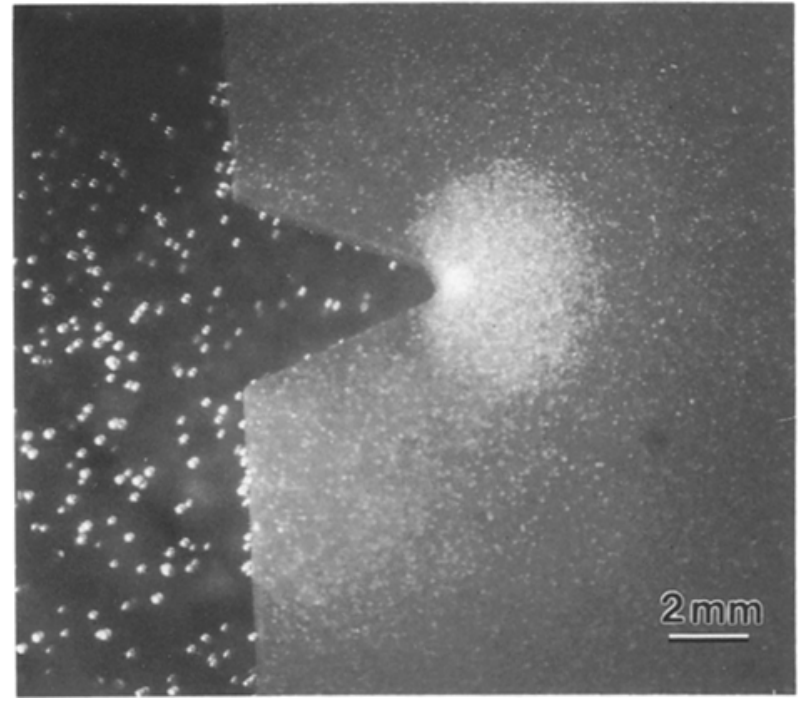

Figure 34 Optical micrograph of a DN-4PB sample of a DER $331 /$ Pip/CTB(10) taken using bright field. Note that the $10 \mathrm{mil}$ radius notch (blunt) induces the formation of a circular cavitation zone.

for this system. Therefore, we propose that reducing the rubber particle size would be necessary for the cavitation/shear banding mechanism to occur.

A highly cross-linked epoxy (DER 331/DDS) was modified with 10 p.h.r. MBS rubber particles with an average particle diameter of $0.2 \mu \mathrm{m}$. This material has a $T_{\mathrm{g}}$ of $196^{\circ} \mathrm{C}$, as measured using DSC, and a $K_{\text {IC }}=0.7 \mathrm{MPa} \mathrm{m}^{1 / 2}$. The compressive yield stress is $136 \mathrm{MPa}$. Using Irwin's formula for the formal plastic zone as an estimate of the process zone gives a value of the process zone size of $1.5 \mu \mathrm{m}$. The fracture toughness increases by $120 \mathrm{~J} \mathrm{~m}^{-2}$ when these smaller particles are used. This increase in toughness is not remarkable. However, examination of a thin section taken from a DN-4PB specimen of this material reveals the presence of a small plastic zone not unlike those zones seen for the DGEBA/Pip/CTBN materials (see Fig. 35) which have a much more ductile matrix. Clearly, the use of submicrometer particles is needed to exploit the voiding/shear banding mechanism for toughening these very brittle epoxies.

In this particular example, we have purposely ignored the role of the cavitation resistence of the rubber particle and the ease of the matrix to shear yield (its "toughenability"). We are well aware that the particle size is not the only factor controlling the fracture toughness. However, the fact that the smaller particles 


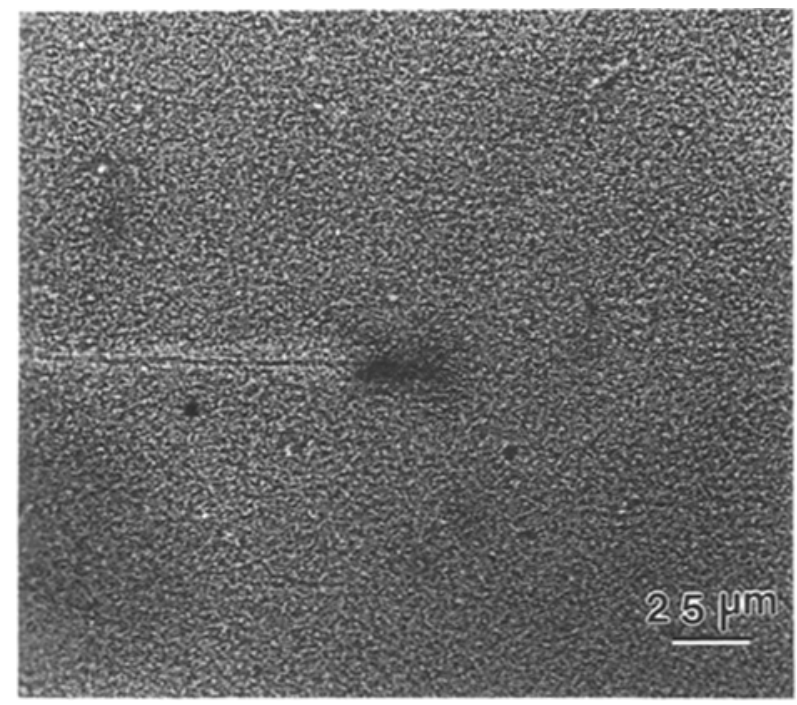

Figure 35 Optical micrograph of a thin section taken mid-plane and near the crack tip of a DN-4PB sample of a DER 331/DDS/ MBS(10). Note the use of smaller particles enables the formation of a damage zone.

do create a small plastic zone is at least consistent with the concept proposed here.

\subsection{The origin of toughness}

In an overview of toughening mechanisms, Hertzberg [34] makes a useful distinction between two sets of toughening mechanisms. The first set of these toughening mechanisms are intrinsic in nature and reflect basic differences in matrix ductility and plastic flow. The second set of these toughening mechanisms are extrinsic in nature and involve events occurring in the wake and/or at the crack tip. The effect of these mechanisms is to shield the crack tip from the full impact of the crack driving force, thus effectively reducing the applied $K$.

Argon [35] has rationalized the magnitude of the fracture toughness of neat epoxy by the mechanism of crack tip shielding. According to Argon, shielding is by plastic deformation in an inelastic zone surrounding the crack tip. The results of our DN-4PB experiments are consistent with this mechanism because a birefringent zone of a few micrometres is observed. The size of this observed plastic zone is on the same order of magnitude as that calculated by Argon.

Argon also estimates the shielding effect when cavitating rubber particles are used to toughen epoxy. Argon states that the additional toughness provided by rubber modification results primarily from an effective reduction of the plastic resistance and hence, a larger plastic zone which provides a greater shielding effect. However, the estimated amount of shielding due to the plastic zone induced by the rubber particles is not sufficient to explain the measured fracture toughness, and Argon attributes the additional shielding to the cavitation of the rubber particles. Our results refute this simple analogy. The addition of the various types of rubber particles to the epoxy system used in this work results in the same reduction in yield stress, yet the increases in fracture toughness are not the same. Moreover, the CTB-modified epoxy possesses the lowest yield stress yet it is the least effective. Additional shielding due to cavitation cannot be used to explain these differences in measured toughness. The resistance to cavitation of the various rubber particles has been shown to be increasing for those modified epoxies with greater fracture toughness. At present, the model proposed by Argon does not take into account the morphological influences and the causal relationship between rubber particle cavitation and induced shear banding.

Evans $e t$ al. [27] has proposed a rubber-toughening model for polymers in an attempt to account for the contributions of rubber particle bridging, cavitation and shear bands. The modest increase in toughness of the CTB-modified epoxies can be accounted for by a bridging mechanism which we have shown to occur. The contribution to the increase in toughness due to shear banding and then cavitation cannot be estimated by the formalism proposed by Evans $e t$ al. Our first objection to this model is that the sequence of events has the wrong order. This work has shown, once again, that cavitation precedes shear band formation. A second objection is that the additive relationship assumed for plastic dilatation and shear banding is incorrect and a causal relationship between these two deformations should be modelled. Finally, the Evans model postulates that the toughening effect in the yielded zone is multiplied by bridging particles. This postulate has not found confirmation in the present results.

\subsection{The issue of synergism}

Many investigators $[6,11,16,17]$ have shown that the addition of bisphenol-A to a CTBN-modified epoxy gives a bimodal particle size distribution and an even tougher epoxy. Some investigators $[16,17]$ have attributed this increase in toughness to a "synergistic effect". However, we believe that the enhanced toughness is a result of decreasing the cross-link density of the epoxy through chain extension. Bascom et al. [17] have claimed that a bimodal distribution of rubber particle sizes is beneficial in rubber-modified epoxies without resorting to matrix modifiers. Unfortunately, these researchers were unable to detect the large particles after curing. While these claims of synergism due to bimodal particle size distributions are not based on concrete evidence the idea is certainly intriguing.

The model proposed by Evans et al. [27] suggests that a multiplicative effect, i.e. synergism, should be expected when the bridging mechanism occurs in addition to the plastic dilatation/shear banding mechanism. The epoxy/rubber blend containing both 5 p.h.r. CTB particles which simply bridge the crack and 5 p.h.r. CTBN-8 particles which cavitate and induce shear bands was produced in an effort to verify this prediction experimentally. The result is a rubber modified epoxy with a bimodal particle size distribution. However, our results are not as promising in terms of measuring a synergism in the increase of fracture toughness. Fig. 36 is a plot of $G_{I C}$ versus the weight fraction CTBN-8 for the 10 p.h.r. CTB/CTBN blends. The toughness of these CTB/CTBN blends are 


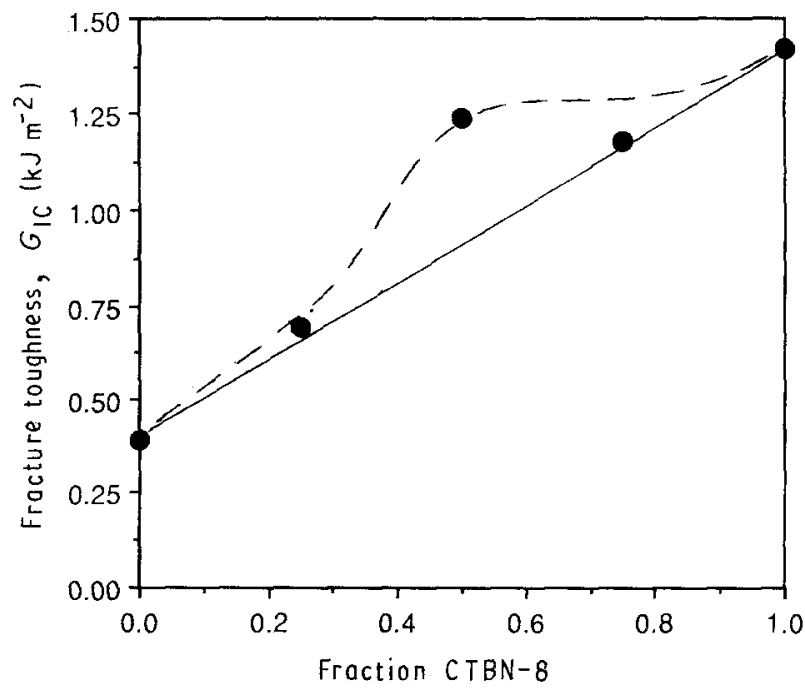

Figure 36 Plot of fracture toughness versus CTBN/CTB fraction for epoxies containing 10 p.h.r. rubber. Bridging particles appear to interact with particles that cavitate and enhance shear banding.

lower than the value for an epoxy modified with 10 p.h.r. CTBN-8. However, the value is higher than one would expect from a simple rule of mixtures $\left(925 \mathrm{~J} \mathrm{~m}^{-2}\right)$.

At present our results indicate that no synergistic effects occur between bridging particles and cavitating particles. However, there is evidence of synergistic effects in hybrid materials containing glass spheres and rubber particles as shown by Kinloch et al. [36]. These researchers have produced modified epoxies cured with piperidine which have a Young's modulus of $2.6 \mathrm{GPa}$ and a $G_{\mathrm{IC}}$ of $5.8 \mathrm{~kJ} \mathrm{~m}^{-2}$ at $50^{\circ} \mathrm{C}$. Their work suggests a synergism between crack pinning [35] and crack blunting mechanisms [37].

\section{Conclusions}

A DGEBA epoxy cured with piperidine has been modified with serveral different elastomers which result in a two-phase material containing rubbery particles of various sizes embedded in an epoxy matrix. The acrylonitrile content in the liquid elastomers controls the particle size. Rubber-modified epoxies containing rubber spheres with diameters ranging from $2-200 \mu \mathrm{m}$ were produced. A rubber-modified epoxy containing $0.2 \mu \mathrm{m}$ particles was produced using a commercially available MBS, core/shell modifier. Bimodally dispersed particle sizes were produced by mixing various rubber modifiers together.

In contrast to our previous conclusions $[5,6]$, which were based on a relatively narrow range of particle sizes, we found in this work that the fracture toughness is very dependent on particle size, where small particles are more efficient in producing a toughening effect than large particles. The origin of this particle size dependence arises from the role played by the particle, which is governed by the size of the process zone. Large rubber particles lying outside the process zone are only able to act as bridging particles which provide only a modest increase in fracture toughness. Small rubber particles which lie in the process zone are forced to cavitate by the large hydro- static stress component that exists in the process zone. The cavitated particles in turn relieve the plane strain constraint and thereby facilitate shear yielding.

This work clearly shows that the sequence of events in rubber-modified epoxies toughened by a cavitation/shear banding mechanism is as follows: first, internal cavitation of the rubber particles and then, subsequent shear band formation in the epoxy matrix. A probable explanation of this behaviour is once again proposed but perhaps stated differently. In a stress state where the hydrostatic tensile component is large, as is the case at a crack tip, the magnitude of the concentrated deviatoric stress in the vicinity of the rubber particle is insufficient to promote shear yielding (bearing in.mind that the difference in bulk moduli between rubber and epoxy is not nearly as great as the difference in their Young's moduli). The internal cavitation of the rubber particle relieves the plane strain constraint by effectively reducing the bulk modulus and now the magnitudes of the concentrated deviatoric stresses are sufficient for shear yielding. This causal relationship is often neglected in the current models for rubber-toughening $[27,35]$. The need for internal cavitation of the rubber particle has been questioned by others $[37,38]$, but these researchers have only considered the case of uniaxial tension, which we have shown to be quite different than the case of the triaxial stress state at the crack tip.

The core/shell rubber particles have been shown to provide the greatest toughening effect (out of those modifiers studied in this work). The underlying cause appears to be related to the cavitational resistance of the particle and should not be confused with a compliance effect as modelled by Boyce et al. [30]. Apparently, a greater cavitational resistance allows a greater build-up of strain energy prior to the cavitation of the particles and subsequent cavitation enables the formation of shear bands to proceed at a faster rate. Therefore, more shear bands can form before the plastic zone cleaves and the net result is a larger plastic zone. A more detailed investigation addressing this issue of rubber particle cavitation resistance is in progress with the hope that new, tougher thermosetting materials can be produced without the sacrifice of cross-link density, hence maintaining a high glass transition temperature.

The notion that a bimodal rubber particle size distribution should result in a greater increase in fracture toughness in rubber-modified epoxies has been disproved on several morphological scales. When $2 \mu \mathrm{m}$ particles are combined with $0.2 \mu \mathrm{m}$ particles, no synergistic toughening was found. When $100 \mu \mathrm{m}$ particles are combined with $2 \mu \mathrm{m}$ particles, again no synergistic toughening was found. However, there is some evidence of interactions between bridging particles and cavitating particles and this will be the subject of a future study.

Tensile dilatometry is useful for monitoring the effect of rate and temperature on those mechanisms that occur in uniaxial tension. However, these mechanisms may or may not occur at the crack tip. The 4PB-DN technique is a useful method for generating mature plastic zones for inspection using various 
microscopic methods. Optical microscopy has been found to be useful for detecting rubber particle cavitation, particle bridging, shear banding, crack path deflection, and particle particle interactions. These sub-surface inspections are certainly more useful than the conventional SEM analysis.

The quantification of the contributions of the individual toughening mechanisms to the overall fracture toughness has not been successful. The stress state dependence of individual mechanisms and more importantly, the causal relationships are difficult to model. Progress in the area can only be made by the careful inspection of the plastic zones which occur at crack tips while systematically varying the physical properties of the matrix, particle and perhaps the interface. Research in this direction is in progress with the goal of developing novel "rigid" toughening particles.

\section{Acknowledgements}

The authors acknowledge the generosity of Dr C. K. Riew, B. F. Goodrich Co., for providing the liquid rubbers and Drs P. Yang and H. J. Sue, Dow Chemical Co., for providing the epoxy resin. The majority of this work was funded by the National Science Foundation (Materials Research Group DMR-8708405). This work was also partially funded by a grant from the B. F. Goodrich Company.

\section{References}

1. J. N, SULTAN, R. C. LiABle and F. J. McGARRY, Polym. Symp. 16 (1971) 127

2. J. N. SULTAN and F. J. McGARRY, Polym. Engng Sci. 13 (1973) 29.

3. A. C. GARG and Y. W. MAI, Comp. Sci. Technol 31 (1988) 179.

4. E. J. KRAMER, in "Advances in Polymer Science", edited by H. H. Kausch, Vol. 52/53 (Springer-Verlag, Berlin, 1983) Ch. 1.

5 A. F. YEE and R. A. PEARSON, J. Mater. Sci. 21 (1986) 2462.

6. R. A. PEARSON and A. F. YEE, ibid. 21 (1986) 2475.

7. W. D. BASCOM, R. L. COTTINGTON, R. L. JONES and P. PEYSER, J. Appl. Polym. Sci. 19 (1975) 2425.

8. W. D. BASCOM and R. L. COTTINGTON, J. Adhesion 7 (1976) 333.

9. A. J. KINLOCH, S. J. SHAW, D. A. TOD and D. L. HUNSTON, Polymer 24 (1983) 1341

10. Idem, ibid. 24 (1983) 1355
11. A. J. KINLOCH and D. L. HUNSTON, J. Mater. Sci. Lett. 5 (1986) 909.

12. R. A. PEARSON and A. F. YEE, J. Mater. Sci. 24 (1989) 2571

13. S. KUNZ-DOUGLASS, P. W. R. BEAUMONT and M. F ASHBY, ibid. 15 (1980) 1109.

14. S. WU, Polymer 26 (1985) 643.

15. A. MARGOLINA and S. WU, ibid. 29 (1988) 2170.

16. C. K. RIEW, E. H. ROWE and A. R. SIEBERT, ACS Adv. Chem. Ser. 154 (1976) 326.

17. W. D. BASCOM, R. Y. TING, R. J. MOULTON, C. K. RIEW and A. R. SIEBERT, J. Mater. Sci. 16 (1981) 2657.

18. W. F. BROWN and J. E. SRAWLEY, ASTM STP 381 (American Society for Testing and Materials, Philadelphia, PA, 1965) p. 13.

19. C. B. BUCKNALL, "Toughened Plastics" (Applied Science, London, 1977).

20. M. A. MAXWELL and A. F. YEE, Polym. Engng Sci. 21 (1981) 205

21. H. J. SUE and A. F. YEE, J. Mater. Sci. 24 (1989) 1447.

22. H. J. SUE, R. A. PEARSON, D. S. PARKER, J. HUANG and A. F. YEE, Polym. Preprints 30 (1988) 147.

23. A. S. HOLIK, R. P. KAMBOUR, S. Y. HOBBS and D. G. FIN K, Microstruct. Sci. 7 (1979) 357.

24. D. HEIKENS, S. D. SJOERDSMA and W. J. COUMANS, $J$. Mater. Sci. 16 (1981) 429.

25. P. B. BOWDEN, in "The Physics of Glassy Polymers", edited by R. N. Haward (Wiley, New York, 1973) Ch. 5.

26. H. L. EWALDS and R. J. H. WANHILL, "Fracture Mechanics" (Edward Arnold, London, 1984).

27. A. G. EVANS, Z. B. AHMAD, D. G. GILBERT and P. W. R. BEAUMONT, Acta Metall 34 (1986) 79.

28. K. T. FABER and A. G. EVANS, ibid. 31 (1983) 565.

29. Idem, ibid. 31 (1983) 577.

30. M. E. BOYCE, A. S. ARGON and D. M. PARKS, Polymer 28 (1987) 1680.

31. R. J. M. BORGGREVE, R. J. GAYMANS and J. SCHUIJER, ibid. 30 (1989) 71.

32. R. J. M. BORGGREVE, R. J, GAYMANS, and H. M. EICHENWALD, ibid. 30 (1989) 78.

33. G. R. IRWIN, Appl. Mater. Res. 3 (1964) 65.

34. R. W. HERTZBERG, "Deformation and Fracture Mechanics of Engineering Materials", 3rd Edn (Wiley, New York, 1989).

35. A. S. ARGON, in "ICF7: Advances in Fracture Research", Vol. 4, edited by K. Samala, K. Ravi-Chander, D. M. R. Taplin and P. Rama Rao (Pergamon Press, New York, 1989).

36. A. J. KINLOCH, D. L. MAXWELL and R. J. YOUNG, $J$. Mater. Sci. 20 (1985) 4169.

37. M. E. J. DEKKERS, S. Y. HOBBS and V. H. WATKINS, ibid. 23 (1988) 1225.

38. F. J. GUILD and R. J. YOUNG, ibid. 24 (1989) 2454.

Received 26 March

and accepted 19 November 1990 